\title{
SITUACIONES ACTUALES EN LA FRONTERA DEL PRINCIPIO DE CULPABILIDAD
}

\author{
Current situations in the boundary of the culpability principle
}

Jaime Winter Etcheberry*

\begin{abstract}
Resumen: El presente trabajo analiza las situaciones actuales que se encuentran en la frontera del principio de culpabilidad en el contexto de los principios limitativos del ius puniendi en la legislación y doctrina chilenas. Tratando de resolver las situaciones anteriores, se busca un concepto de principio de culpabilidad que incluya el injusto y la culpabilidad como elementos del delito, de modo que se plantea poder incorporar (a estas categorías) la mayoría de los efectos que se atribuyen al principio. A partir de esto se analizan, como situaciones límite del principio, la responsabilidad penal de las personas jurídicas, la responsabilidad por la posición (principalmente por omisión) en el derecho penal internacional y el derecho penal de la empresa y organizaciones, las medidas de seguridad que se imponen de manera copulativa con una pena y la culpabilidad en la Ley de Responsabilidad Penal Adolescente.
\end{abstract}

Palabras clave: Principio de culpabilidad - responsabilidad penal de las personas jurídicas - responsabilidad por omisión de los superiores - medidas de seguridad y pena - responsabilidad penal adolescente.

\begin{abstract}
This paper analyzes the current situations which are located in the boundary of the culpability principle in the context of the limitative principles of the ius puniendi (as recognized in the continental legal tradition). For this purpose, we analyze this principle considering the actus reus and the mens rea requirements, so that it is possible to introduce (in these categories) most of the consequences that are attributed to that principle. Based on this, we analyze this principle in limit situations such as the corporate criminal responsibility, the responsibility due to the position (mainly by omission) in the international criminal law and the criminal law of corporations and other organizations; the complementary-to-punishment safety measures; and in the Youth Criminal Responsibility Act.
\end{abstract}

Keywords: Culpability principle - corporate criminal liability - superior responsibility (by omission) - safety measures and punishment - youth criminal liability.

\footnotetext{
*Abogado, Universidad de Chile. Becario DAAD y estudiante de doctorado de la Justus-LiebigUniversität Gießen, Alemania. Correo electrónico: jaimewinter@gmail.com.

El presente es parte de una serie de artículos sobre los principios limitativos del IusPuniendi realizados en conjunto con Jorge Cabrera Guirao (Abogado, Universidad de Chile y LL.M., Universidad de Pensilvania). A él se deben parte de las correcciones de este trabajo y las atinentes referencias al Derecho penal norteamericano. Igualmente agradezco al Profesor Gonzalo Medina Schulzpor la lectura y comentarios que se han visto reflejados en la versión final de este trabajo. Agradezco también la ayuda del estudiante de Derecho Gonzalo Winter Etcheberry. Los errores que subsistan son, por supuesto, propios.
}

Este artículo fue recibido el 17 de octubre del año 2012, siendo aprobada su publicación con fecha 5 de diciembre de 2012. 
Winter - Situaciones actuales en la frontera del principio de culpabilidad

\section{Introducción general}

Generalmente se identifica el Derecho penal, más que cualquier otra rama del Derecho, como un Derecho de principios. La lesión de bienes jurídicos que lleva a cabo la intervención punitiva requiere la más potente restricción y ella debe estar regulada por los principios que desde larga data son considerados como esenciales para limitar el Derecho penal. Sin embargo, el mundo ha avanzado mucho desde el surgimiento del Derecho penal liberal y corresponde volver a preguntarse sobre la vigencia, validez y estado de dichos principios.

El presente pertenece a una serie de trabajos que buscan explorar cada uno de los más conocidos principios del Derecho penal, revisando aquellas áreas sensibles en que vale la pena poner la atención. Esto irá en sentidos diferentes dependiendo de las características del principio y la situación analizada. En algunos casos se observará que el contenido del principio nunca estuvo claro o que existe una controversia al respecto. En otros casos, se verá que si bien el principio está claro, su utilidad o su aplicación nunca lo ha estado realmente. En cuanto a la práctica, se podrá observar que en áreas relevantes existen casos en que los principios no están siendo aplicados o se están recorriendo sus fronteras. Esto podrá significar una necesidad de la modernidad, en algunos casos, y, en otros, una peligrosa flexibilización de los límites del Derecho penal.

En general, los tratadistas nacionales no analizan de manera sistemática y conjunta los principios del Derecho penal, y no se refieren a cuáles son sus roles dentro del sistema ni a qué nivel actúan. En algunos casos, por ejemplo, más que principios se muestran como características del Derecho penal, de las cuales no se extrae ningún valor. Sin embargo, en conjunto ayudan a mostrar los contornos de la idea de Derecho penal como ha sido concebida hasta ahora.

Hacer un listado es inevitablemente una tarea arbitraria, pero con el afán de mantenerse apegado a la realidad chilena, se ha tomado la enumeración hecha por Garrido Montt (legalidad, intervención mínima, exclusiva protección de bienes jurídicos, humanidad, culpabilidad, proporcionalidad y resocialización), ${ }^{1}$ agregándose solamente, por su importancia, el ne bis in idem.

En este trabajo se revisan aquellos casos que transitan en las fronteras del principio de culpabilidad. Dentro de ellos se analizan la responsabilidad penal de las personas jurídicas, la responsabilidad de los superiores tanto en el Derecho penal internacional como en el Derecho penal de la empresa y otras organizaciones, la posibilidad de aplicar una medida de seguridad copulativamente con una pena y la culpabilidad de los menores de edad en la Ley de Responsabilidad Penal Adolescente. Para dicho efecto, en lo que sigue, es necesario esbozar un concepto de principio de culpabilidad.

\footnotetext{
${ }^{1}$ Garrido Montt, Mario: Derecho Penal, Parte General, t. I, 2001, pp. 29 y ss.
} 


\section{Generalidades sobre el principio de culpabilidad}

$\mathrm{Al}$ principio de culpabilidad se le atribuye una gran importancia dentro del sistema penal, $^{2}$ se le llama -imitando la fórmula de Feuerbach para el principio de legalidad $^{3} \mathrm{y}$, por tanto, equiparándolos- nullam poena sine culp $a^{4} \mathrm{y}$ se ha dicho que se lo puede considerar como "faro iluminador de cualquier enjuiciamiento penal." Sin embargo, con razón ha dicho Kaufmannque se lo tiende a considerar una obviedad que no es objeto de mayores discusiones, ${ }^{6}$ en cuanto a que su contenido exacto no es absolutamente claro.

Como punto de partida, la formulación nullam poena sine culpa indica que la sanción penal presupone la culpabilidad. ${ }^{7}$ Esto, sin embargo, no permite reducir el grado de indeterminación.

Paralelamente a la culpabilidad como fundamento de la pena es posible advertir que la culpabilidad es un elemento específico del delito. ${ }^{8}$ Una primera aproximación a su concepto sería equiparar el principio de culpabilidad con el elemento del delito culpabilidad, como lo hacen algunos autores.'

\footnotetext{
2 Vid. referencias y opinión del autor en Kunsemüller Loebenfelder, Carlos: Culpabilidad y Pena, 2001, pp. 18 y 19. También Cury, Enrique: Derecho Penal, Parte General, 2005, p. 385. Garrido Montt señala que "La culpabilidad se alza en el derecho penal moderno como su pilar fundamental". Garrido Montt, Mario: Derecho Penal, t. I (nota 1), p. 198. La noción no es ajena al commonlaw, así Oliver Wendell Holmes señaló que incluso un perro distingue entre ser pateado y cuando alguien se tropieza con él ("[...]even a dogdistiguishesbeingstumbledover and beingkicked[...]"). Holmes, Oliver Wendell: The Common Law, 2009, p. 3.

3 Nulla poena sine lege. Feuerbach, Paul Johann Anselm: Lebrbuch des gemeinen in Deutschland gültigen peinlichen Rechts, 1812, p. 22.

4 Jakobs, Günther: Derecho Penal. Parte General, 1995, p. 588; Politoff L., Sergio, Matus A., Jean Pierre y Ramírez G., María Cecilia: Lecciones de Derecho Penal, Parte General, 2003, p. 72. La referencia, aunque no en latín, suele estar presente en el tratamiento del principio. Vid. Kindhäuser, Urs: Strafrecht. AllgemeinerTeil, 2011, p. 178; Cury, Enrique: Derecho Penal, 2005 (nota 2), p. 386; Etcheberry, Alfredo: Derecho Penal. Parte General, t. I, 1998, p. 323; Garrido Montt, Mario: Derecho Penal, t. I (nota 1), p. 198

5 SCS, Nivaldo Cáceres Salinas y otros, 12.08.2008, Rol N 1933-2007, Considerando Trigésimo Quinto.

${ }^{6}$ Kaufmann, Arthur: Das Schuldprin₹ip, 1961, p.7

7 Kindhäuser, Urs: Strafrecht. (nota 4), p. 178. Wessels, Johannes y Beulke, Werner: Strafrecht, Allgemeiner Teil, 2011, p. 4

${ }^{8}$ Kindhäuser, Urs: Strafrecbt. (nota 4), p. 178

9 Garrido Montt asume un concepto basado en la proporcionalidad; sin embargo, todo su desarrollo es referente a la culpabilidad como elemento del delito, sin perjuicio de que además sostenga que representa la proscripción de sancionar meras causaciones. Vid. Garrido Montt, Mario: Derecho Penal, t. I (nota 1), pp. 47-49. Igualmente Cury sostiene que con el elemento culpabilidad del delito se satisface el principio no hay pena sin culpa, sin perjuicio de que posteriormente derive de este principio consecuencias propias de otras concepciones del principio de culpabilidad. Cury, Enrique: Derecho Penal, 2005 (nota 2), pp. 386 y ss. Jakobs, por ejemplo, al tratar el elemento del delito culpabilidad le atribuye las características del principio de culpabilidad. Vid. Jakobs, Günther: Derecho Penal (nota 4), p. 596. Así también Etcheberry, Alfredo: Derecho Penal, t. I (nota 4), p. 278. Se puede decir que los dos primeros autores reducen el principio de
} 
Winter - Situaciones actuales en la frontera del principio de culpabilidad

El concepto de culpabilidad como elemento del delito se ha identificado con la idea de reproche que puede hacérsele al sujeto por su conducta. ${ }^{10}$ Específicamente está constituido por la imputabilidad, es decir, que el individuo sea capaz de comprender la prohibición, excluyéndose a los menores y dementes; que el individuo haya sido consciente de la probibición, excluyéndose los casos del llamado error de prohibición, en que el individuo no sabía que algo no estaba permitido; y que el individuo haya podido dirigir su actuar según la norma, es decir, que no haya sido objeto de algún tipo de coacción para realizar la conducta. ${ }^{11}$

A esto subyace el sempiterno problema del libre albedrío, sobre la verdadera capacidad del individuo de decidir su actuar, más allá de determinaciones biológicas o del ambiente y hasta qué punto esto puede ser demostrable. ${ }^{12}$ Una forma de resolver esta pregunta se presenta en teoría empíriconormativa de Roxin, donde la culpabilidad se vincula con la función preventiva de la pena. La prohibición está dirigida a personas que entienden la misma, que tienen consciencia de ella y que puede conformar su actuar a la norma, de modo que si la persona observa que a otro que no tiene estas características no se le impone pena, no podrá asumir que a él mismo no se le impondrá la pena o que la norma deja de tener validez. ${ }^{13}$ Esto deriva de que se trata al hombre como si fuera libre ${ }^{14}$ basado en que en el caso concreto existían las condiciones normales con que un individuo puede motivarse según la norma. ${ }^{15}$

Sin embargo, este elemento del delito no alcanza a cubrir, según la mayoría de la doctrina, la totalidad del alcance del concepto del principio de culpabilidad.

culpabilidad al elemento del delito culpabilidad, mientras que los otros dos amplían el elemento del delito culpabilidad, de modo que coincida con el principio de culpabilidad.

${ }^{10}$ En la doctrina chilena, vid. entre otros, Cury, Enrique: Derecho Penal, 2005 (nota 2), p. 385 y ss.; Etcheberry, Alfredo: Derecho Penal, t. I (nota 4), p. 272; Garrido Montt, Mario: Derecho Penal, t. II (nota 1), p. 196; Politoff L., Sergio, Matus A., Jean Pierre y Ramírez G., María Cecilia: Lecciones de Derecho Penal. Parte General (nota 4), p. 72.

11 Vid. por ejemplo, Kindhäuser, Urs: Strafrecht. (nota 4), p. 181. En general la doctrina chilena asume estos elementos como los propios de la culpabilidad. Así, Cury, Enrique: Derecho Penal, 2005 (nota 2), p. 402 y ss.; Garrido Montt, Mario: Derecho Penal, t. II (nota 1), p. 208. En todo caso, en los autores que consideran al dolo y la culpa como parte integrante de la culpabilidad incluyen aparte los elementos aquí señalados. Por ejemplo, Politoff L., Sergio, Matus A., Jean Pierre y Ramírez G., María Cecilia: Lecciones de Derecho Penal. Parte General (nota 4), p. 246, Etcheberry, Alfredo: Derecho Penal, t. I (nota 4), p. 277 y ss.

12 Tema imposible de tratar acá. Básico al respecto Engisch, Karl: Die Lebre von der Willensfreibeit in der strafrechtsphilosophischen Doktrin der Gegenwart, 1963. Engisch describe las posiciones básicas en relación a la llamada guerra de las escuelas. Entre los clásicos (pp. 7 y 8) destaca a Binding para quien la pena es una retribución a la culpabilidad y ésta un presupuesto de la primera. Para que exista culpabilidad, además, el hombre debe ser libre. Con respecto a los "modernos" (pp. 8 y ss.) que se forman alrededor de Liszt, que, desde un punto de vista determinista, considera que se debe renunciar a la culpabilidad y que no existe merecimiento en la pena, sino que solamente finalidad o protección. La conducta del individuo no es libre, sino que el delito es necesariamente e inevitablemente consecuencia de las condiciones dadas.

${ }^{13}$ Cfr. Roxin, Claus: Strafrecht, Allgemeiner Teil, 2006, pp. 872 y ss.

${ }^{14}$ Ibid., p. 868.

${ }^{15}$ Cfr. Ibid. 
Principalmente debido al concepto que ha dado el Tribunal Constitucional Alemán, ${ }^{16}$ tiende a incluirse dentro de él, también en Chile, ${ }^{17}$ al principio de proporcionalidad, ${ }^{18}$ incluso por autores que expresamente tratan a la proporcionalidad de manera independiente. ${ }^{19}$ Esto se identifica con la común formulación que la culpabilidad es la medida de la pena, ${ }^{20}$ aunque también existe hoy una tendencia a señalar que es el límite de la pena. ${ }^{21}$

Por ejemplo, una teoría sobre el fundamento de la pena que con claridad recurre al concepto de culpabilidad es la de Roxin. Su teoría se estructura alrededor del concepto de prevención: el fundamento de la pena viene dado por su utilidad para prevenir que el mismo individuo u otros realicen comportamientos delictivos futuros. ${ }^{22}$ Por otra parte, siguiendo al Tribunal Constitucional Alemán, considera que la culpabilidad debe ser el limite superior de la pena: ${ }^{23}$ la pena no puede exceder a la culpabilidad del individuo, pero si puede ser menor a ella cuando por razones de política criminal no se justifique la imposición de una sanción más alta. ${ }^{24}$

Sin embargo, esto no está complementado con un concepto previo de culpabilidad que pueda ser funcional a esta determinación. Por el contrario, su concepto normativo de culpabilidad como elemento del delito es completamente incompatible con esta concepción, donde el juicio que se hace es el de ausencia de causales de exculpación, más que como un reproche. ${ }^{25}$

La posibilidad -limitada- ${ }^{26}$ de graduar estos elementos no permite comprender cómo la culpabilidad puede representar el límite principal de la medida de la pena. Las características de la culpabilidad como elemento del delito tienen un carácter primordialmente dicotómico -existe o no culpabilidad-, de modo que al asumirlo como medida de la pena, es evidente que falta agregar una dimensión adicional al principio de culpabilidad que no está contenida en el elemento del delito.

\footnotetext{
${ }^{16}$ Sentencia del Bundesverfassungsgericht de 25 de Octubre de 1966, en causa 506/1963.

17 Cury, Enrique: Derecho Penal, 2005 (nota 2), p. 390; Politoff L., Sergio, Matus A., Jean Pierre y Ramírez G., María Cecilia: Lecciones de Derecho Penal. Parte General (nota 4), p. 253; Kunsemüller Loebenfelder, Carlos: Culpabilidad y Pena (nota 2), pp. 32 y 33.

${ }^{18}$ Vid., por ejemplo, Jakobs, Günther: Derecho Penal (nota 4), p. 588 y 589.

${ }^{19}$ Garrido Montt, Mario: Derecho Penal, t. I (nota 1), pp. 47 y ss.

20 Por todos, Cury, Enrique: Derecho Penal, 2005 (nota 2), p. 390.

${ }^{21}$ Wessels, Johannes y Beulke, Werner: Strafrecht (nota 7), p. 4.; Kindhäuser, Urs: Strafrecht. (nota 4), p. 178. Evidentemente en conexión, como se verá, con la teoría mixta de Roxin.

22 Roxin, Claus: Strafrecht(nota 13), pp. 85 y ss.

${ }^{23}$ Ibid., pp. 91 y ss.

24 Ibid., pp. 91 y 92.

25 Vid. notas al pie 13 a 15 y explicación correspondiente.

${ }^{26}$ Se puede hablar de que un menor tiene imputabilidad disminuida, o se considera que el error de prohibición vencible fundamente un reproche menor que la ausencia de error. Igualmente sería posible hablar de la relevancia de la coacción en un caso concreto.
} 
Una primera posibilidad, derivada de la concepción clásica del delito ${ }^{27}$ y que goza de cierta popularidad, implica considerar integrante al principio de culpabilidad al dolo y la culpa. ${ }^{28}$ Se entiende que un hecho es objeto de mayor reproche si se realiza con dolo que con culpa, de modo que representan en sí mismos graduaciones de la culpabilidad. ${ }^{29}$ Sin embargo, no es posible ver aquí la dimensión completa de la gravedad del ilícito. Para eso es necesario ver la conducta misma del individuo y su significado. ${ }^{30}$

Así, existe una tendencia a incluir en el principio de culpabilidad elementos del injusto mismo: ${ }^{31}$ En general, es posible caracterizarla en ese sentido como la necesidad de que el individuo haya realizado una conducta con dolo o culpa y sin elementos que impidan que se le realice el reproche penal, dicho de otra manera, el principio de culpabilidad exige que la sanción se aplique basado en una conducta del individuo, que éste haya decidido y realizado de manera libre y con comprensión de su significado.

Esto significa considerar que el principio de culpabilidad comprende al menos tres elementos: la culpabilidad como elemento del delito, los otros elementos de injusto (incluidos el dolo y la culpa) y debe encontrarse en una relación de proporcionalidad con la pena. ${ }^{32}$

No es posible llevar a cabo aquí una determinación más acabada del principio de culpabilidad y su distinción con la culpabilidad como elemento del delito, sin embargo, del concepto aquí utilizado pueden derivarse la mayoría de los efectos que se le atribuyen a este principio.

En primer lugar, se señala que no es posible sancionar a personas sólo por causar un hecho, sino que debe basarse en el dolo o culpa del individuo. ${ }^{33}$ Esta es la prohibición de responsabilidad objetiva, que en su extremo puede prescindir no sólo de la conexión subjetiva con el hecho, sino que incluso del nexo causal. ${ }^{34} \mathrm{La}$ institución de la responsabilidad objetiva tiene cierta aceptación en el Derecho civil, especialmente en ámbitos de actividades peligrosas. Así el dueño de un vehículo debe responder solidariamente por los perjuicios causados por el

\footnotetext{
27 La teoría clásica del delito incluyen en la culpabilidad al dolo y la culpa. Con distintos fundamentos, siguen en Chile esta posición Politoff, Matus y Ramírez, así como Etcheberry. Vid. nota al pie 11.

28 Vid., por ejemplo, Bacigalupo, Enrique: Principios constitucionales del derecho penal, 1999, p. 139

${ }^{29}$ Cfr. Etcheberry, Alfredo: Derecho Penal, t. I (nota 4), pp. 276 y 277. En su caso, lo argumenta en el sentido de incluir el dolo y la culpa en la culpabilidad y no en la tipicidad.

${ }^{30}$ En contra, basado en una posición en extremo finalista, Cury, para quien el injusto realmente se radica en el tipo subjetivo, de modo que la gravedad del hecho es parte del dolo del individuo, Cfr. Cury, Enrique: Derecho Penal, 2005 (nota 2), pp. 390 y 391.

${ }^{31}$ Jakobs incluye dentro de su concepto de culpabilidad como elemento del delito al injusto mismo, vid. Jakobs, Günther: Derecho Penal (nota 4), p. 596. En el mismo sentido Etcheberry, Alfredo: Derecho Penal, t. I (nota 4), p. 278. Ambos ya referidos en nota al pie 9.

32 Wessels, Johannes y Beulke, Werner: Strafrecht (nota 7), p. 148 y 149.

${ }_{33}$ Garrido Montt, Mario: Derecho Penal, t. I (nota 1), pp. 47 a 49.

${ }^{34}$ Etcheberry, Alfredo: Derecho Penal, t. I (nota 4), p. 324.
} 
conductor del mismo, aunque no haya sido siquiera pasajero. ${ }^{35}$ Igualmente, por citar un caso de actividad paradigmáticamente riesgosa, hay responsabilidad objetiva en los daños causados en materia de energía nuclear. ${ }^{36}$ Semejante clase de responsabilidad se encuentra en principio proscrita del Derecho penal.

Derivado de lo anterior, suele señalarse como excepción al principio no hay pena sin culpa a los llamados delitos calificados por el resultado que son aquellos en que se aumenta la punibilidad de una conducta ilícita si esta provoca determinados resultados que no son ni previstos ni queridos por el autor. ${ }^{37}$ Esto deriva del principio más amplio que establece la prohibición del versari in re ilícita, ${ }^{38}$ que se formula como el que se ocupa de una cosa ilícita responde del caso fortuito, es decir, quien por mero accidente provoca un daño al realizar una conducta ilícita debiera responder por ese daño a título de dolo, aun cuando este no fuere ni querido ni previsible. ${ }^{39}$

Por otra parte, también el principio de culpabilidad tiende a presentarse como el fundamento de la prohibición de imponer penas en virtud del mero carácter del individuo. ${ }^{40}$ Esto representa el paso del llamado Derecho penal de autor al Derecho penal del becho. ${ }^{41}$

Al respecto, no sin cierta razón, Bustos ha criticado el principio de culpabilidad, señalando que estaría vacío de contenido y que su análisis sólo se justifica por razones históricas. ${ }^{42}$ En su concepción, la necesidad de dolo o culpa (es decir, la prohibición de responsabilidad objetiva) se deriva del principio de exclusiva protección de bienes jurídicos y se concreta en el concepto de tipicidad; la proporcionalidad representa un principio distinto; y la necesidad de que exista una conducta que se le atribuya al individuo pertenece a la teoría del injusto y no de la culpabilidad. ${ }^{43}$

\footnotetext{
35 Artículo 174 Ley 18.290 del Tránsito. De las infracciones a los preceptos del tránsito será responsable el conductor del vehículo.

El conductor y el propietario del vehículo, a menos que este último acredite que el vehículo fue usado sin su conocimiento o autorización expresa o tácita, son solidariamente responsables de los daños y perjuicios que se ocasionen con motivo del uso del vehículo; todo sin perjuicio de la responsabilidad de otras terceras personas, en conformidad a la legislación vigente.

${ }^{36}$ El art. 49 de la Ley 18.302 de Seguridad Nuclear señala: La responsabilidad civil por daños nucleares será objetiva y estará limitada en la forma que establece esta ley.

37 Vid. Cury, Enrique: Derecho Penal, 2005 (nota 2), pp. 347, 387 y 388; Etcheberry, Alfredo: Derecho Penal, t. I (nota 4), p. 326. Garrido Montt, Mario: Derecho Penal, t. II (nota 1), p. 178.

38 Politoff L., Sergio, Matus A., Jean Pierre y Ramírez G., María Cecilia: Lecciones de Derecho Penal. Parte General (nota 4), p. 251.

39 Vid.; Etcheberry, Alfredo: Derecho Penal, t. I (nota 4), p. 328; Garrido Montt, Mario: Derecho Penal, t. II (nota 1), p. 179.

${ }^{40}$ Cury, Enrique: Derecho Penal, 2005 (nota 2), p. 389. Etcheberry, Alfredo: Derecho Penal, t. I (nota 4), p. 330.

41 Vid. Politoff L., Sergio, Matus A., Jean Pierre y Ramírez G., María Cecilia: Lecciones de Derecho Penal. Parte General (nota 4), p. 171.

42 Bustos Ramírez, Juan y Hormazábal Malarée, Hernán, Lecciones de Derecho Penal, vol. I, 1997, p. 70.

${ }^{43}$ Ibid.
} 
Al respecto, es posible señalar, en primer lugar, que parece mucho más adecuado vincular al dolo y a la culpa con el principio de culpabilidad que con el de exclusiva protección de bienes jurídicos: Los bienes jurídicos se ven igualmente en riesgo en actividades peligrosas con o sin el dolo o culpa del agente. ${ }^{44}$ Lo que cambia es la valoración de la conducta del individuo, es decir, su culpabilidad. En cuanto la separación de injusto, como categoría del delito y culpabilidad, como se señalara, se tiende a incluir el injusto dentro de la culpabilidad. Por último, en cuanto a su relación con el principio de proporcionalidad, si bien una buena parte de la doctrina lo considera como parte del principio de culpabilidad, y nada obsta a que así sea, solamente por razones vinculadas a la exposición, aquí se tratará como un principio aparte.

Con estas explicaciones previas es posible referirse al tema de su reconocimiento constitucional. Parte de la doctrina ${ }^{45}$ considera que el principio de culpabilidad puede extraerse del artículo $19 \mathrm{~N}^{\circ} 3$ inciso $6^{\circ}$ que señala que "la ley no podrá presumir de derecho la responsabilidad penal". Esto, que sin duda garantiza el principio de inocencia, implicaría que como presupuesto a la norma tiene que existir un Derecho penal basado en la culpabilidad. Sin embargo, es difícil extraer realmente de dicha norma tal principio, en virtud de que simplemente pone de manifiesto que en los casos en que sea necesaria la culpabilidad esta no podrá presumirse, dejando abierta la posibilidad de que en ciertos casos no se exija. ${ }^{46}$ En ese sentido parece deseable que a futuro tuviera un reconocimiento en Ley Fundamental.

En lo que sigue, se analizarán algunos temas que, si bien no representan necesariamente vulneraciones flagrantes al principio de culpabilidad, navegan por sus fronteras y llevan a que sea posible preguntarse si no corresponde volver a analizar su contenido. Los distintos casos se vinculan con distintas dimensiones del principio de culpabilidad. Así, la responsabilidad penal de la persona jurídica dice relación con la prohibición de imputar un hecho ajeno (prohibición de responsabilidad objetiva o vicaria), pero también con la necesidad de imputar un hecho (prohibición de responsabilidad por el carácter), además de la necesidad de autoconsciencia (culpabilidad en sentido amplio, así como la necesidad de dolo y culpa). La responsabilidad de los superiores por omisión en el Derecho penal internacional y de la empresa y otras organizaciones se vincula directamente con la prohibición de responsabilidad objetiva o vicaria, al hacérselo responsable por hechos de terceros. Por otra parte, la imposición de medidas de seguridad

\footnotetext{
${ }^{44}$ Cabe señalar que Bustos y Ramírez definen la exclusiva protección de bienes jurídicos señalando que "el Estado tiene limitado su ius puniendi sólo a la incriminación de conductas dolosas o culposas que lesionen bienes jurídicos". Así, incluyen el tipo subjetivo en este principio, sin embargo, de la propia formulación del principio se hace evidente que es un presupuesto previo y distinto. Cfr. Ibíd., p. 69.

45 Cury, Enrique: Derecho Penal, 2005 (nota 2), p. 388; Kunsemüller hace una revisión de la doctrina a este respecto: Kunsemüller Loebenfelder, Carlos: Culpabilidad y Pena (nota 2), p. 235 y ss.

${ }^{46}$ Etcheberry, Alfredo: Derecho Penal, t. I (nota 4), pp. 67 y 68.
} 
REJ - Revista de Estudios de la Justicia - No 17 - Año 2012

copulativamente con una pena puede ser analizada de diversos puntos de vista. Si se analiza de modo conjunto con la pena, se relaciona con la culpabilidad en el sentido de proporcionalidad, mientras que si se observa como una medida independiente afecta las otras dimensiones del principio de culpabilidad. Por último, en el caso de la responsabilidad de los adolescentes, el problema apunta directamente a la culpabilidad como elemento del delito.

\section{Ley de Responsabilidad Penal de las Personas Jurídicas}

En primer lugar, recientemente y de manera sorpresiva ${ }^{47}$ se introdujo en Chile con fecha 25 de noviembre de 2009 la responsabilidad penal de las personas jurídicas. ${ }^{48}$ $\mathrm{Si}$ bien es posible concordar con Hernández en que "[...] ciertamente debe celebrarse que el resultado del trabajo legislativo parezca en lo fundamental acertado $[\ldots],{ }^{49}$ buena parte de la doctrina reaccionó airada considerando que era "[u]n retroceso de siglos", ${ }^{50}$ que "[...]más que una renovación, constituye una involución del sistema penal a formas de responsabilidad objetiva que se había luchado por superar, y que en gran medida vienen impuestas en los organismos internacionales desde el derecho anglosajón, cuyo atraso en esta materia es paradigmático" "51 y que "[...] sea cual fuere la vía en la que se pretendan enmarcar las sanciones de la persona jurídica, ésta debe ser ajena en lo sustancial al viejo y noble Derecho Penal, bajo cuyo prestigio ha pretendido ampararse formalmente esta ley[...]". ${ }^{52}$ Todas estas críticas apuntan a la supuesta renuncia al principio de culpabilidad, que es, hoy en día, tal vez el tema más controvertido en el ámbito de la responsabilidad penal de las personas jurídicas. ${ }^{53}$ Tanto es así, que en Italia, considerándose que de la Constitución se podría extraer el principio de culpabilidad, ${ }^{54}$ se optó por no llamar a la responsabilidad penal, sino que responsabilidad administrativa de las empresas por el delito, ${ }^{55}$ siendo que cabe poca duda de que sea penal. ${ }^{56}$ Una opción semejante se había hecho en el proyecto de la

\footnotetext{
47 Así también Hernández Basualto, Héctor: "La introducción de la responsabilidad de las personas jurídicas en Chile”, Politica Criminal 9, 2010, p. 208.

${ }^{48}$ Ley 20.393 que Establece la responsabilidad penal de las personas jurídicas en los delitos de lavado de activos, financiamiento del terrorismo y delitos de cohecho que indica. Publicada en el Diario Oficial con fecha 02.12.2009.

${ }^{49}$ Hernández Basualto, Héctor: "La introducción de la responsabilidad..." (nota 47), p. 211.

${ }^{50}$ Velozo, Francisco: “Un retroceso de siglos”, Estrategia, 4.12.2009, p. 2.

${ }^{51}$ Cury, Enrique: "Personas jurídicas y derecho penal”, El Mercurio, 23.11.2009, p. A2.

52 Ortiz Quiroga, Luis: "Responsabilidad de las personas jurídicas”, El Mercurio, 15.12.2009, p. A2.

53 Gómez-Jara Díez, Carlos: “Autoorganización empresarial y autorresponsabilidad empresarial: Hacia una verdadera responsabilidad penal de las personas jurídicas", Revista Electrónica de Ciencia Penaly Criminología 8, 2006, p. 16.

54 Esto se extrae, en principio, del escueto inciso primero del artículo 27 de la Constitución que señala: La responsabilità penale è personale.

55 Decreto Legislativo 8 giugno 2001, n. 231: Disciplina della responsabilita' amministrativa delle persone giuridiche, delle societa' e delle associazioni anche prive di personalita' giuridica, a norma dell' articolo 11 della legge 29 settembre 2000, n. 300.

${ }^{56}$ De Maglie, Cristina: "Countries with criminal liability: Italy", en Gobert, James y Pascal, Ana María, European Development in Corporate Criminal Liability, 2011, pp. 252 y 253.
} 
Winter - Situaciones actuales en la frontera del principio de culpabilidad

ley chilena, donde se hablaba de responsabilidad legal, ${ }^{57}$ lo que finalmente fue modificado a responsabilidad penal siguiendo la opinión de algunos expertos. ${ }^{58}$

La responsabilidad penal de las personas jurídicas es un fenómeno mundial ${ }^{59}$ y tiene que ver con la necesidad de control de las empresas. La tendencia

57 Vid. Artículo $1^{\circ}$ del Proyecto de Ley, en Historia de la Ley 20.393, p. 11.

58 Así, por ejemplo, Clara Szczaranski (Historia de la Ley 20.393, p. 36) y Gonzalo Medina Schulz (Historia de la ley 20.393, p. 54).

${ }^{59} \mathrm{El}$ pionero en este tema son los EE.UU. que ya al final del s. XIX y con claridad a principios del XX ya permitían la responsabilidad penal de las personas jurídicas (Laufer, William S.: Corporate Bodies and Guilty Minds, The failure of Corporate Criminal Liability, 2006, p. 11-19). Aunque no existe una ley única al respecto, es claro que en el Reino Unido se acepta este tipo de responsabilidad. Para ello es importante considerar la Corporate Manslaughter Act 2007 y la Bribery Act 2010 (Gobert, James: “Country Reports, Countries with Criminal Liability: UK”. en Gobert, James y Pascal, Ana María, European Development in Corporate Criminal Liability, 2011, p. 315 y ss.). Holanda fue uno de los primeros países en introducir la responsabilidad penal de las personas jurídicas en 1976, aunque ya en 1951 existía un tipo de responsabilidad similar (De Doelder, Hans: "Criminal Liability of Corporations: A Dutch Update", en Sieber, Ulrich, Danneker, Gerhard, Kindhäuser, Urs, Vogel, Joachim y Walter, Tonio, StrafrechtundWirtschaftStarfrecht: Festschrifffir Klaus Tiedemann, 2008 y Ramkissoon, Melanie: "Countries with criminal liability. Country Report. The Netherlands", en Gobert, James y Pascal, Ana María, European Development in Corporate Criminal Liability, 2011, p. 278). Igualmente temprano, en 1984, fue introducida en Portugal (Pascal, Ana María y Ramkissoon, Melanie: "Countries with Criminal Liability. Country Report: Portugal", en Gobert, James y Pascal, Ana María, European Development in Corporate Criminal Liability, 2011, p. 289). En Francia se introdujo en 1994 (Bouvais, Pascal: "Countries with Criminal Liability, France", en Gobert, James y Pascal, Ana María, European Development in Corporate Criminal Liability, 2011, p. 240), luego en Finlandia en 1995 (Gobert, James: "Countries with criminal liability. Country Report: Finland”, en Gobert, James y Pascal, Ana María, European Development in Corporate Criminal Liability, p. 234), en Dinamarca en 1996 (Pascal, Ana María: "Countries with criminal Liability. Country Report: Denmark", en Gobert, James y Pascal, Ana María, European Development in Corporate Criminal Liability, 2011, pp. 221 y ss.) y Estonia en 2002 (Pascal, Ana María: Countries with criminal liability. Country report: Estonia", en Gobert, James y Pascal, Ana María, European Development in Corporate Criminal Liability, 2011, p. 229). En Europa Continental el proceso está vinculado a la adopción del Segundo Protocolo de la Convención para la Protección de los Intereses Financieros de la Unión Europea. Así, Bélgica en 1999 (Ramkissoon, Melanie: "Countries with criminal Liability. Country Report: Belgium”, en Gobert, James y Pascal, Ana María, European Development in Corporate Criminal Liability, 2011, p. 214), Eslovaquia también en 1999 (Dillon, Janis: "Countries with criminal liability. Country report: Slovenia”, en Gobert, James y Pascal, Ana María, European Development in Corporate Criminal Liability, 2011, p. 204), Polonia en 2002 (Pascal, Ana María: "Countries with criminal liability. Country Report: Poland", en Gobert, James y Pascal, Ana María, European Development in Corporate Criminal Liability, 2011, p. 283), Lituania en 2003 (Soloveicikas, Deividas: "Countries with criminal liability. Country report: Lithuania”, en Gobert, James y Pascal, Ana María, European Development in Corporate Criminal Liability, 2011 p. 263), Rumania en 2004 (Pascal, Ana María: "Countries with criminal liability. Country report: Romania”, en Gobert, James y Pascal, Ana María, European Development in Corporate Criminal Liability, 2011, p. 296), Austria también en 2004 (Mitgutsch, Ingrid: "Countries with criminal liability. Country report: Austria", en Gobert, James y Pascal, Ana María, European Development in Corporate Criminal Liability, 2011, pp. 209 y ss.), Luxemburgo en 2010 (Pascal, Ana María y Dillon, Janis: "Countries with criminal Liability. Country report: Luxembourg”, en Gobert, James y Pascal, Ana María, European Development in Corporate Criminal Liability, 2011, p. 275) y España también en 2010 (Díez Ripollés, José Luis: "La responsabilidad penal de las personas jurídicas. Regulación española", InDret 1, 2012, p. 3). Como se señaló, en Italia se introdujo en 2001, sin perjuicio de que no es completamente penal (De Maglie, Cristina: "Countries with criminal liability: Italy [nota 56], pp. 250 y ss.). Por otro lado, en Australia se introdujo en 1995 
REJ - Revista de Estudios de la Justicia - No 17 - Año 2012

a que este control se haga mediante sanciones penales, y no mediante otras formas de control administrativo, se basa en general en los siguientes argumentos: No siempre se puede sancionar penalmente a la persona física (irresponsabilidad organizada); aun identificando a la persona física, sancionarla es insuficiente; y las sanciones administrativas contra las empresas serían insuficientes. ${ }^{60}$

La irresponsabilidad organizada representa la existencia de estructuras dentro de la organización que impiden dar con un responsable al interior de ella. ${ }^{61}$ Esto puede tener que ver con dos elementos distintos. Por un lado, puede que la responsabilidad se difumine al interior de la organización, así, no todos los elementos de la responsabilidad se encontrarán en un mismo sujeto. ${ }^{62}$ Por otro lado, la empresa es un lugar particularmente propicio para generar un control de los flujos de información, de modo que es fácil evitar que la información llegue a terceros. ${ }^{63} \mathrm{Al}$ no poder darse con un responsable físico, parece necesario sancionar a la organización.

En segundo lugar, muchas veces incluso aunque se identifique un individuo dentro de la organización, su sanción puede ser insuficiente. Por un lado, esto tiene que ver con la posibilidad de la existencia de una actitud criminógena de grupo debido a una mala cultura corporativa. ${ }^{64}$ La sanción a un individuo específico que comete el delito deja intacta la estructura que promueve su comisión. ${ }^{65}$ Por otro lado, existen dos fenómenos vinculados con lo mismo que hacen que se pierda la función preventiva de la sanción penal: Por una parte, es posible que la sanción se sitúe en los niveles más bajos de la empresa, sin que se pueda alcanzar a quienes han tenido una labor más relevante en la organización del hecho y, por otra parte, es posible que se creen chivos expiatorios expresamente establecidos para hacerse cargo de la totalidad de la responsabilidad. ${ }^{66}$

Por último, es posible sostener que las sanciones administrativas serían suficientes, considerando que muchas veces la multa administrativa es más alta que la multa penal. Ante esto se responde señalando que el Derecho penal tiene un contenido simbólico particular. ${ }^{67}$ Por otro lado, que conviene evitar la multiplicidad de

\footnotetext{
-aplicable desde 2001- (Hill, Jennifer: "Corporate Criminal Liability in Australia: An Evolving Corporate Governance technique?", Journal of Business Law (Workingpaper 03-10), 2003, 15 y 16).

60 Silva Sánchez, Jesús María, "La Responsabilidad jurídica de las personas jurídicas y las consecuencias accesorias del art. 129 del Código Penal", en Manuales de formación continuada, Consejo General del Poder Judicial, 2001, p. 314.

${ }^{61}$ Cfr. Ibid., p. 315.

${ }^{62}$ Ibid.

${ }^{63}$ Nieto Martín, Adán: La responsabilidad penal de las personas jurídicas: un modelo legislativo, 2008, p. 41.

${ }^{64}$ Ibid., p. 40.

${ }^{65}$ Silva Sánchez, Jesús María: "La Responsabilidad jurídica...” (nota 60), p. 316 y 317.

66 Nieto Martín, Adán: La responsabilidad penal... (nota 63), p. 39. Sin perjuicio que este autor considere que son parte de la irresponsabilidad organizada. Más adecuado es aquí hablar de responsabilidad organizada o responsabilidad desorganizada (así, Rotsch, Thomas: "Criminal Compliance", InDret 1, 2012, p. 7).

${ }^{67}$ Silva Sánchez, Jesús María, "La Responsabilidad jurídica..." (nota 60), p. 318.
} 
Winter - Situaciones actuales en la frontera del principio de culpabilidad

procesos mediante la reunión en uno solo del proceso contra la persona natural y la jurídica. ${ }^{6}$ Por último, se habla de una supuesta incapacidad de un proceso administrativo de hacerse cargo de problemas de criminalidad organizada. ${ }^{69}$

Sin perjuicio de lo anterior, ante la inexistencia de un sistema de responsabilidad administrativa general en Chile, queda claro que la necesidad de cumplir con celeridad ciertas exigencias internacionales ${ }^{70}$ no dejaba otra posibilidad que establecer una responsabilidad penal. ${ }^{71}$

En este ámbito de cosas, existen al menos dos modelos para imputar responsabilidad a la persona jurídica: El modelo de atribución del hecho ajeno o de responsabilidad vicaria y el modelo de responsabilidad originaria de la organización. ${ }^{72}$

En el primero, se "imputa transfiriendo a la empresa todo acto realizado por un agente suyo en el ejercicio de su actividad con la intención de favorecerla" (las cursivas son nuestras). ${ }^{73}$ Así, con la simple identificación de autor dentro de la organización es posible imputar el hecho a la empresa misma, siempre y cuando el culpable físico haya actuado con la intención de beneficiar a la misma y mediante una actuación en el marco y naturaleza del empleo, ${ }^{74}$ sin perjuicio de versiones que centran la imputación sólo en la conducta de los administradores de la empresa. ${ }^{75}$

Semejante modelo, que fue el seguido en una primera época por el sistema norteamericano y se mantiene hasta el día de hoy morigerado, ${ }^{76}$ representa un evidente caso de responsabilidad objetiva. ${ }^{77}$ Simplemente se la atribuye a la

${ }^{68}$ Ibid., pp. 319 y 320.

${ }^{69}$ Ibid., p. 320 y 321.

${ }^{70}$ Chile debía cumplir algunos requisitos exigidos por OCDE para su ingreso como miembro antes de la cita que tenía en diciembre de 2009.

${ }^{71}$ Señalado por René Abeliuk Manasevich, Vid. Historia de la ley 20.393, pp. 35-37.

${ }^{72}$ En general, es la clasificación que hace la mayoría de la doctrina. Así, Nieto Martín, Adán: La responsabilidad penal... (nota 63), pp. 85 y ss. Silva Sánchez, Jesús María, "La Responsabilidad jurídica..." (nota 60), pp. 321 y ss. Gómez-Jara Díez, Carlos: La Responsabilidad penal de las empresas en los EE.UU., 2006. pp. 43 y ss. y luego 83 y ss. Valga señalar que la responsabilidad criminal sin culpa en el derecho de los Estados Unidos de América corresponde, a responsabilidad vicaria (vicarious liability) y responsabilidad estricta (strict liability). Existirá responsabilidad estricta cuando se pueda obtener una condena basado en la prueba de que el imputado ha cometido un acto prohibido por ley y el ejercicio del cuidado debido no resulte en una defensa. La responsabilidad vicaria, en cambio, se extiende a situaciones en que se atribuye responsabilidad criminal respecto de las acciones de un tercero, usualmente un empleado. La aceptación de responsabilidad sin culpa, sin embargo, no resulta unánime. En efecto, el Código Penal Modelo (Model Penal Code) rechaza la imposición de responsabilidad criminal sin culpa en caso que la pena incluya la privación de libertad. No obstante lo anterior, ambos tipos de responsabilidad penal han sido considerados como constitucionales. Sobre la materia vid. Robindon, Paul: "Mens Rea", en Dressler, Joshua, Encyclopaedia of crime $-j$ justice, 2002, pp. 995-1006.

73 Nieto Martín, Adán: La responsabilidad penal... (nota 63), p. 85.

${ }^{74}$ Gómez-Jara Díez, Carlos: La Responsabilidad penal de las empresas... (nota 72), pp. 46-49.

75 Ibid., pp. 50 y ss.

${ }^{76}$ Ibid., pp. 43 y ss. Y luego 50 y ss.

77 Así también Nieto Martín, Adán: La responsabilidad penal... (nota 63), p. 115. 
organización un hecho ajeno, sin exigir siquiera un nexo causal. Si bien se sostiene que es un sistema simple, ${ }^{78}$ las mayores críticas vienen dadas por su bajo rendimiento para resolver los problemas que justifican la responsabilidad de las personas jurídicas. ${ }^{79}$ En el caso de la irresponsabilidad organizada puede no existir un sujeto físico cuya responsabilidad pueda atribuirse a la empresa ${ }^{80} \mathrm{o}$, cuando se identifica con la acción de los superiores, promueve la búsqueda de chivos expiatorios $^{81}$ y $\sin$ hacer referencia a un déficit de organización no se valora suficientemente a las entidades que tienen una adecuada estructura organizativa, ${ }^{82}$ es decir, se criminaliza la actividad empresarial antes que la realizada de mala manera.

En cambio, el modelo de responsabilidad originaria se concentra en "[si] la empresa ha sido diligente en la prevención y descubrimiento de hechos delictivos". ${ }^{83}$ Así, la responsabilidad de la empresa dependerá de su propio actuar, y en él debe basarse su culpabilidad.

La pregunta fundamental es cómo puede esta concepción ser compatible con el principio de culpabilidad, es decir, cómo puede conectarse a la empresa con el delito específico, cómo puede entenderse que ella lo ha cometido y cómo puede entenderse que en ella concurren tanto los elementos del injusto como de la culpabilidad.

La primera respuesta dogmática relevante en este sentido es la de Heine, quien en realidad renuncia a un concepto de culpabilidad por el hecho, sino que recurre a una culpabilidad por la configuración anterior de la empresa. El delito de la empresa es estar mal organizada y el delito específico que se ha cometido no sería más que una condición objetiva de punibilidad. ${ }^{84}$

Fisse y Braithwaite consideran que las empresas actúan mediante políticas $\operatorname{corporativas}^{85}$ y que la culpabilidad de la empresa estaría dada por un comportamiento posterior al hecho ilícito consistente en no tomar las medidas necesarias de prevención o corrección. ${ }^{86}$ Esto implica renunciar a una culpabilidad tradicional, entendiendo que no está claro en qué consiste y cómo se puede probar el mens rea (aspecto subjetivo del delito) de la empresa con respecto al delito. Así, su propuesta es meramente pragmática, enfocada en la prevención de delitos que la

\footnotetext{
${ }^{78}$ Crítico ante la aseveración, Ibid., p. 85.

79 Vid. Ibid., pp. 120 y ss.

80 Silva Sánchez, Jesús María, "La Responsabilidad jurídica...” (nota 60), p. 324, aunque lo relativiza, p. 325.

81 Nieto Martín, Adán: La responsabilidad penal... (nota 63), p. 121.

${ }^{82}$ Cfr. Ibid., p. 123 y ss.

83 Ibid., p. 85.

${ }^{84}$ Heine, Günther: Die strafrechtliche Verantwortlichkeit von Unternehmen, 1995, pp. 288 y ss.

${ }^{85}$ Explicado por Gómez-Jara Díez, Carlos: La Responsabilidad penal de las empresas... (nota 72), p. 88.

86 Explicado por Nieto Martín, Adán: La responsabilidad penal... (nota 63), p. 139; y Gómez-Jara Díez, Carlos: La Responsabilidad penal de las empresas... (nota 72), p. 90.
} 
Winter - Situaciones actuales en la frontera del principio de culpabilidad

empresa pueda cometer en el futuro, y no responde al problema de la culpabilidad. ${ }^{87} \mathrm{Al}$ igual que en los casos anteriores lo que se crea es un delito especial (offense of reactive non compliance) ${ }^{88}$ y no vinculan el actuar de la empresa con el delito cometido, sino que con no tomar las medidas necesarias para que no vuelva a ocurrir ${ }^{89}$

Estas tesis, aunque atractivas, no resuelven en ningún caso el problema de la culpabilidad por el hecho. Asimismo, son incompatibles con el texto de la Ley chilena. El modelo que por el que optó el legislador chileno es uno reforzado, ${ }^{90}$ donde copulativamente debe existir un hecho punible realizado por una persona física en beneficio de la organización, aunque no se pueda determinar la identidad de la misma, ${ }^{91}$ y, además, el delito debe haber sido consecuencia de un déficit organizacional de la persona jurídica (incumplimiento de los deberes de dirección y supervisión). ${ }^{92}$ No es posible renunciar a acreditar la relación entre el defecto de organización y el delito cometido.

En un sentido similar a las anteriores se dirige la tesis de Lampe. Como punto de partida sostiene que un sistema de injusto constituido ${ }^{93}$ no solamente es

${ }^{87}$ Ibid.

88 Valga señalar, en todo caso, que ofrecerían un interesante análisis del significado de la culpabilidad. Para ellos el disvalor social de la conducta no está solamente dado por la conducta previa de la empresa, sino que también por su conducta posterior. Repara en ello Nieto Martín, Adán: La responsabilidad penal... (nota 63), p. 140.

89 Ibid., p. 140.

${ }^{90}$ Nieto habla de sistemas mixtos, en que la imputación se hace a través de un modelo vicarial, pero se regula a través de la culpabilidad. Esto hacen las Sentencing Guidelines en EE.UU. Ibíd., p. 86. Aquí el sistema vicarial y el originario cumplen funciones diversas: uno imputa (responsable o no responsable) y el otro regula (grado de culpabilidad). Sin embargo, también usa el concepto para referirse al sistema italiano, que es similar al chileno (pp. 177 y 178). En el caso chileno la imputación sólo se puede obtener de la existencia copulativa de ambos y, por eso, es preferible hablar de reforzado.

91 Artículo $5^{\circ}$ Ley 20.393 inciso final: También podrá perseguirse dicha responsabilidad cuando, habiéndose acreditado la existencia de alguno de los delitos del artículo $1^{\circ}$ y concurriendo los demás requisitos previstos en el artículo $3^{\circ}$, no haya sido posible establecer la participación de el o los responsables individuales, siempre y cuando en el proceso respectivo se demostrare fehacientemente que el delito debió necesariamente ser cometido dentro del ámbito de funciones y atribuciones propias de las personas señaladas en el inciso primero del mencionado artículo $3^{\circ}$.

92 Artículo $3^{\circ}$ Ley 20.393 incisos primero y segundo: Atribución de Responsabilidad Penal. Las personas jurídicas serán responsables de los delitos señalados en el artículo $1^{\circ}$ que fueren cometidos directa e inmediatamente en su interés o para su provecho, por sus dueños, controladores, responsables, ejecutivos principales, representantes o quienes realicen actividades de administración y supervisión, siempre que la comisión del delito fuere consecuencia del incumplimiento, por parte de ésta, de los deberes de dirección y supervisión.

Bajo los mismos presupuestos del inciso anterior, serán también responsables las personas jurídicas por los delitos cometidos por personas naturales que estén bajo la dirección o supervisión directa de alguno de los sujetos mencionados en el inciso anterior.

${ }^{93}$ Una crítica a la distinción entre sistema de injusto constituido y sistema de injusto simple, y en especial a la distinción dentro de las distintas clases de sistema de injusto constituido, en Mañalich, Juan Pablo: "Organización Delictiva. Bases para su elaboración dogmática en el derecho penal chileno", Revista Chilena de Derecho 2, 2011, pp. 280 y ss. 
"más que la suma de sus partes, sino que una institución que no depende del cambio de sus miembros". "Así, señala que el delito mismo cometido sería una expresión de la existencia de la filosofía de la empresa. ${ }^{95}$ Lampe tiene además la virtud de separar aquellos casos en que existe una filosofía criminal del grupo -similar a la actitud criminal de la empresa de Schünemann- ${ }^{96}$ y aquellos en que sólo hay déficits organizacionales, ${ }^{97}$ lo que sería equivalente a la diferenciación entre dolo y culpa. ${ }^{98}$

Como es posible observar, ninguna de estas teorías atribuye realmente el hecho punible original a la organización. En cambio, crean un tipo especial para ella, haciéndose cargo del déficit organizacional. Estas teorías se acercan -expresamente en Heine ${ }^{99}$ y Lampe- ${ }^{100}$ a una de las prohibiciones que establece el principio de culpabilidad consistente en no criminalizar el carácter del individuo, que es precisamente lo que se hace en este caso.

No es extraño en ese sentido que, por ejemplo, Silva Sánchez considere que las reacciones contra las empresas son verdaderas medidas de seguridad que miran a la peligrosidad futura de la organización y no penas que miran retrospectivamente a lo realizado por ella. ${ }^{101}$ Sin embargo, esto no representa más que un cambio de nomenclatura. ${ }^{102}$ La finalidad de las medidas de seguridad es principalmente preventivo especial, precisamente porque no es posible que el destinatario de la norma sea capaz de conformarse respecto de ella por un déficit en su capacidad de comprensión de la norma (falta de imputabilidad). Sin embargo, no cabe duda que la mayoría ${ }^{103}$ de los modelos pretenden tener efectos preventivos generales, ${ }^{104}$ en el sentido de lograr que las empresas en general se organicen de acuerdo con la norma.

En todo caso, de todos estos esfuerzos se deriva una conclusión que parece inevitable: no es posible considerar que la culpabilidad en sentido clásico pueda aplicarse a las personas jurídicas. ${ }^{105}$ Ellas no son capaces realmente de acción en un sentido tradicional, no cumplen con el elemento subjetivo propio de los tipos penales y, por sobre todo, no tienen la autoconsciencia necesaria para ser objeto del reproche que implica la culpabilidad.

\footnotetext{
${ }^{94}$ Lampe, Ernst-Joachim: “Systemunrecht und Unrechtssystem”, ZStW 4, 1994, p. 693.

95 Ibid. , p. 732.

96 Schünemann, Bernd: Unternehmenskriminalität und Strafrecht, 1979, p. 22.

${ }^{97}$ Ibid., pp. 707-709.

98 Nieto Martín, Adán: La responsabilidad penal... (nota 63), pp. 138 y 139.

${ }_{99}$ Heine, Günther: Die strafrechtliche Verantwortlichkeit... (nota 83), p. 266.

${ }^{100}$ Lampe, Ernst-Joachim: "Systemunrecht und Unrechtssystem" (nota 94), pp. 732 y 733.

101 Vid. Silva Sánchez, Jesús María, "La Responsabilidad jurídica...” (nota 60), pp. 343 y ss.

102 Cfr. Nieto Martín, Adán: La responsabilidad penal... (nota 63), pp. 102 y 103.

${ }^{103}$ Es posible que el de Frisse y Braithwaite se pueda justificar en términos preventivo-especiales, sin embargo, como se vio, no es compatible con el sistema chileno.

104 Esto, especialmente en sentido de prevención general negativa. Ya ha señalado Jakobs que las medidas de seguridad en general cumplen con una función preventivo general positiva. Jakobs, Günther: Derecho Penal (nota 4), pp. 40 y 41.

105 Silva Sánchez, Jesús María: "La Responsabilidad jurídica...” (nota 60), pp. 334 y ss.
} 
Winter - Situaciones actuales en la frontera del principio de culpabilidad

Interesante resulta entonces la posición de Nieto, quien, siguiendo la tendencia actual, ${ }^{106}$ basa su teoría en una "'personalidad defectuosa', consistente [en] un defecto en la organización permanente, no puntual". ${ }^{107}$ Ante el problema constitucional que esto implicaría, simplemente considera que el límite a la culpabilidad por el carácter tiene que aplicarse a las personas naturales, pero no hay buenas razones para que se aplique también a las empresas; sin embargo, corresponde encontrar un equivalente funcional a la culpabilidad de las personas individuales para los entes colectivos, ${ }^{108}$ el que estaría dado, precisamente, por una forma defectuosa de autoorganización. Así, los intentos por aplicar los conceptos de dolo e imprudencia al ente colectivo no son más que metáforas para referirse a la gravedad del defecto de organización. ${ }^{109}$ Por último, y esto es sumamente valioso, la indeterminación del defecto de organización se ve resuelta haciéndolo sinónimo de la implementación de programas de prevención de delito, ${ }^{110}$ algo que está presente también en la Ley chilena. ${ }^{111}$

Tal vez la teoría más importante en este ámbito sea la de Gómez-Jara, que propone un concepto constructivista ${ }^{112}$ de culpabilidad, que sería funcionalmente equivalente al concepto de culpabilidad individual. ${ }^{113} \mathrm{El}$ punto de partida es una base similar a la de Jakobs. ${ }^{114}$ Para este autor las expectativas de comportamiento (qué van a realizar los otros) son esenciales, porque sin ellas todo contacto social es completamente aleatorio, uno no sabe que esperar de los demás. ${ }^{115}$ Con una conducta contraria a esa expectativa expresada en la norma lo que hace el individuo es declarar con su conducta que esa norma no es válida respecto de él. ${ }^{116}$ $\mathrm{Al}$ imponerse una pena se declara de manera contrafáctica que dicha norma es

106 Ibid., p. 336.

${ }^{107}$ Nieto Martín, Adán: La responsabilidad penal... (nota 63), p. 150.

108 Ibid., p. 151. Con un desarrollo más acabado de por qué los entes colectivos no tienen la protección del principio de culpabilidad, en pp. 115 a 120. Señala que la culpabilidad emana de la dignidad de la persona humana y del derecho al libre desarrollo de la personalidad, lo que no puede ser aplicable a las personas jurídicas que en sí misma son medios, mero objetos, p. 117.

${ }_{109}$ Ibíd., p. 160. Para explicar esto, podemos recurrir a la posición, ya explicada, de Lampe, en que considera que la actitud criminal del grupo es equivalente al dolo y el defecto de organización es equivalente a la imprudencia. En el primer caso se promueve o se acepta la comisión de ilícitos, en el otro no está adecuadamente desarrollada la prevención.

110 Nieto Martín, Adán: La responsabilidad penal... (nota 63), pp. 215 y ss.

111 Artículo $3^{\circ}$ de la Ley 20.393 inciso tercero: "Se considerará que los deberes de dirección y supervisión se han cumplido cuando, con anterioridad a la comisión del delito, la persona jurídica hubiere adoptado e implementado modelos de organización, administración y supervisión para prevenir delitos como el cometido, conforme a lo dispuesto en el artículo siguiente".

En el artículo $4^{\circ}$ de la misma ley está la descripción de qué se entiende por estos programas de cumplimiento y cuál es su contenido mínimo.

112 No es posible hablar de un concepto constructivista sin hacer referencia al trabajo de Laufer, William S.: Corporate Bodies... (nota 59), pp. 70 y ss.

113 Gómez-Jara Díez, Carlos: “Autoorganización empresarial...” (nota 53), pp. 16 y 17.

114 Ibid., p. 17.

${ }^{115}$ Jakobs, Günther: Derecho Penal (nota 4), p. 9 y más desarrollada en página 11.

116 Ibid., p. 13. 
generalmente válida. ${ }^{117}$ Sin embargo, no todos tienen la capacidad de cuestionar la norma. A partir de esto, se pueden hacer tres constataciones básicas que permiten construir la culpabilidad de la organización: En primer lugar, no es posible para el Estado controlar en términos absolutos una empresa, principalmente en aquellos casos en que tiene una alta complejidad interna, de modo que a lo más se puede aspirar a que ella tenga una fidelidad con el Derecho. Esto en la práctica implica que se le reconoce una esfera de autonomía a la organización. ${ }^{118}$ Sin embargo, necesariamente el hecho de que se le reconozca un ámbito de autonomía implica que también se le tiene que reconocer un ámbito de responsabilidad. ${ }^{119}$ Por último, esta situación análoga al estatus de ciudadano (ciudadanía corporativa), implica que la empresa puede participar de manera autónoma en el debate público, es decir, puede contribuir a la creación común de sentido, ${ }^{120}$ en último término, esto significa que puede poner en duda la vigencia de la norma. ${ }^{121}$ La pregunta que subyace es por qué decimos que es la organización la que puede negar la vigencia de la norma y no -solamente- los individuos físicos. La respuesta viene dada por el nivel de complejidad que adquieren las empresas, en las que se puede advertir una verdadera cultura corporativa. ${ }^{122}$ Esa cultura corporativa se caracteriza por ser independiente de sus miembros específicos, los cuales no tienen la capacidad de eliminarla por simple decisión (sí mediante un proceso de cambio del paradigma cultural). ${ }^{123}$ De este modo, propiamente lo que se expresa mediante el actuar de la empresa es su propia identidad y no la de sus miembros. ${ }^{124}$ Esto lleva a una importante conclusión: no todas las organizaciones pueden ser penalmente imputables. Tal como las personas físicas, la empresa debe llegar a una mayoría de edad, ${ }^{125}$ que lo que sucede cuando tiene la complejidad suficiente para desmarcar su identidad de las personas físicas. ${ }^{126}$

Esto presenta, eso sí, al menos dos problemas. El primero y más evidente, es que se requiere que se acepta una teoría subyacente que indudablemente no es la mayoritaria dentro de nuestra doctrina. ${ }^{127}$ No implica adoptar solamente una teoría sobre la responsabilidad de las personas jurídicas, sino que sobre todo el sistema penal. Sin perjuicio de ello, esta teoría sí goza de bastante popularidad cuando se trata de imputar a las organizaciones. ${ }^{128}$

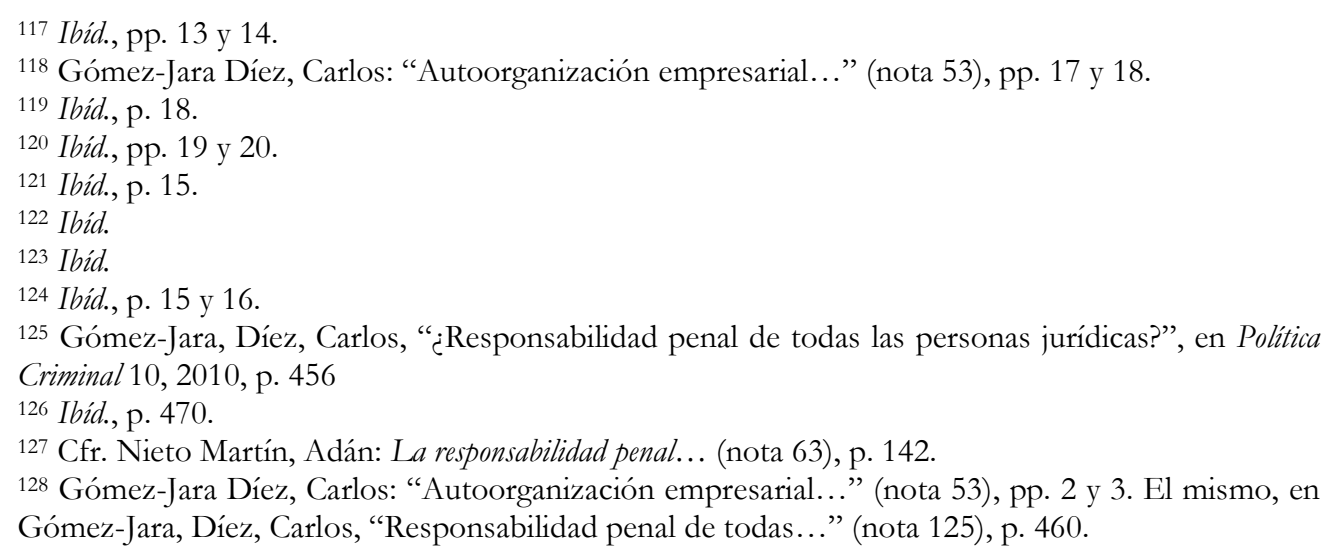


Winter - Situaciones actuales en la frontera del principio de culpabilidad

Sin embargo, incluso aceptando la premisa de la teoría funcionalistasistémica es posible encontrar críticas relevantes a la propuesta de Gómez-Jara y a la culpabilidad de las personas jurídicas en general. Así, el mismo Jakobs ${ }^{129}$ y en nuestro medio Van Weezel ${ }^{130}$ critican la responsabilidad de las personas jurídicas teniendo como base una teoría similar a la de Gómez-Jara. Van Weezel ataca al corazón de la tesis de Gómez-Jara al señalar que el grado de complejidad que alcanzan las empresas, al menos en Chile, no es suficiente para crear una identidad independiente de sus controladores, ${ }^{131}$ comparando la autorreferencialidad de la organización con la de una ameba. ${ }^{132}$ Asimismo, un aspecto central de su crítica está en que el Derecho penal no se tomaría en serio a las empresas, debido a que además de hacerlas responsables a ellas exige un responsable físico (a diferencia, por ejemplo, del Derecho comercial o el administrativo sancionador). ${ }^{133}$ Jakobs, en el mismo sentido, considera que para atribuir culpa la persona debe tener autoconsciencia, debe entenderse a sí misma como libre, algo que difícilmente se puede esperar de una organización. ${ }^{134}$

En fin, no es posible aquí analizar y desarrollar adecuadamente todas estas teorías, pero es evidente la pugna de la responsabilidad penal de las personas jurídicas con el principio de culpabilidad visto en forma tradicional. Si hay que reformular el principio, ampliarlo, crear uno paralelo o simplemente desconocer el carácter penal de las sanciones al ente ${ }^{135}$ es un asunto que seguramente seguirá en el centro del debate jurídico penal por algún tiempo.

\section{Responsabilidad por la posición}

Es innegable el profundo protagonismo que las organizaciones han llegado a tener en el mundo actual, ${ }^{136}$ siendo la ya referida responsabilidad penal de la persona jurídica sólo una reacción a esto. Por otra parte, la existencia de la organización modifica la forma de imputación de las personas naturales que están vinculadas a ella. Así, dentro del contexto de lo que Schünemann ha llamado la responsabilidad

129 Jakobs, Günther: “Strafbarkeit juristische Personen?", en Prittwitz, Cornelius; Baurmann, Michael; Günther, Klaus; Kuhlen, Lothar; Merkel, Reinhard; Nestler, Cornelius y Schulz, Lorenz (coords.), Festschrift für Klaus Lüderssen, 2002.

${ }^{130}$ Van Weezel, Alex: "Contra la responsabilidad penal de las personas jurídicas”, Política Criminal 9 , 2010.

131 Ibid., p. 119.

132 Ibid., p. 125.

133 Ibid., pp. 127 y 128.

134 Jakobs, Günther: “Strafbarkeit juristische Personen?” (nota 129), p. 570 y 571.

${ }^{135}$ Cfr. Silva Sánchez, Jesús María, "La Responsabilidad jurídica...” (nota 60), p. 335.

136 Schünemann, Bernd: Unternehmenskriminalität... (nota 96), pp. 15-18. Tombs ha señalado que "[L]as empresas afectan -o [...] infectan- todas las áreas de nuestras vidas. Y si la ubicuidad de las empresas es, hay que recordarlo, un fenómeno relativamente reciente, más o menos en los últimos 30 años la influencia de las empresas sobre y dentro de nuestras vidas ha crecido de forma exponencial", Tombs, Steve, "Corporations and Health and Safety", en Minkes, John y Minkes, Leonard (eds.), Corporate and White-Collar Crime, 2008, p. 18. 
lo más posible hacia arriba ${ }^{137}$ se ha intentado llegar a la responsabilidad del superior por hechos que ha realizado el subordinado. Claro ejemplo de esto son la construcción por parte de Roxin de la autoría mediata por utilización de un aparato organizado de poder, ${ }^{138}$ que ha sido criticado por la doctrina en términos generales, ${ }^{139}$ pero especialmente en su aplicación para quienes dirigen las empresas. ${ }^{140}$ Asimismo, se presenta como relevante el intento de construir una coautoría del hombre de atrás. ${ }^{141}$

En este contexto, uno de los grandes problemas está muchas veces en la imposibilidad de acreditar la existencia de una orden o instrucción por parte del hombre de atrás y, a partir de esto, se ha sostenido que éste tendría una posición de garante que lo obliga a evitar los delitos que puedan cometer sus subordinados. ${ }^{142}$ Esto se ve reflejado principalmente en los ámbitos en que más relevante son las organizaciones: el Derecho penal de la empresa y el Derecho penal internacional. ${ }^{143}$

La primera aproximación se encuentra en la llamada responsabilidad por el mando o responsabilidad de los superiores en el Derecho penal internacional. ${ }^{144}$ Básicamente consiste en una forma de imputación penal de un superior por no haber hecho todo lo que estaba a su alcance para prevenir que sus subordinados cometieran determinados crímenes, sin haberlos ordenado o inducido directamente, y conociendo el hecho de que iban a ser cometidos o se estaban cometiendo. ${ }^{145}$ Esta institución, originaria del derecho penal internacional, ${ }^{146}$ aparece con claridad ${ }^{147}$ por primera vez en el juicio contra el general Yamashita del ejército japonés, juzgado por la Comisión Militar de Estados Unidos y

\footnotetext{
137 Schünemann, Bernd: "Responsabilidad penal en el marco de la empresa. Dificultades relativas a la individualización de la imputación”, ADPCP LV, 2002, p. 10.

138 Roxin, Claus: Täterschaft und Tatherrschaft, 2000, pp. 242 y ss.

139 Por ejemplo, Haas, Volker: "Kritik der Tatherrschaftlehre", ZStW 119, 2007, pp. 523 y ss.; y, Thomas: "Einheitstäterschaft" statt Tatherrschaft, 2009, pp. 322-331.

140 Existe amplia literatura al respecto, vid., por ejemplo, el propio Roxin en Roxin, Claus: "El Dominio de Organización como forma independiente de Autoría Mediata", Revista de Estudios de la Justicia 7, 2006, en especial pp. 21-22. Rotsch, Thomas: "Die Rechtsfigur des Täters hinter dem Täter bei der Begehung von Straftaten im Rahmen organisatorischer Machtapparate und ihre Übertragbarkeit auf wirtschaftliche Organisationsstrukturen“, NStZ 10, especialmente pp. 493-495. El mismo en Rotsch, Thomas: Individuelle Haftung in Großunternehmen, 1998, pp. 144-147.

${ }^{141}$ Entre nosotros Mañalich, Juan Pablo: "Organización Delictiva...” (nota 93), p. 288.

142 Así, por ejemplo, Stratenwerth, Gunther y Kuhlen, Lothar: Strafrecht Allgemeiner Teil. Die Straftat, 2011, p. 287.

143 Winter Etcheberry, Jaime: La responsabilidad de los superiores en el Derecho penal internacional, 2009, p. 11, notal al pie 30 .

$144 \mathrm{Al}$ respecto, vid., en general, Ibid.; y Ambos, Kai: "Superior Responsibility", en Cassese, Antonio, Gaeta, Paola y Jones, John R. W. D. (coords.), The Rome Statute of the International Criminal Court: A commentary, 2002, pp. 805-851.

145 Winter Etcheberry, Jaime: La responsabilidad de los superiores (nota 143), p. 16.

146 Ambos, Kai: Der Allgemeine Teil des Völkerstrafrechts, 2002, p. 667.

147 Se señala que puede rastrearse hasta el siglo XV o incluso antes. Cfr. Ambos, Kai: "Superior Responsibility" (nota 144), p. 807.
} 
Winter - Situaciones actuales en la frontera del principio de culpabilidad

posteriormente la Corte Suprema de ese país. ${ }^{148}$ El general Yamashita estaba a cargo de las tropas japonesas en las Filipinas durante la Segunda Guerra Mundial. Hacia el final de la guerra Estados Unidos llegó a Manila, donde se produjeron enfrentamientos con las tropas japonesas por alrededor de un mes. Durante ese tiempo, las tropas japonesas torturaron y asesinaron a cerca de 700.000 civiles en lo que se conoce como la Masacre de Manila. El comando de Yamashita se encontraba en las montañas del Baguio, a 200 kilómetros de Manila. La defensa alegó que las comunicaciones se encontraban cortadas, por lo que no pudo comunicarse para ordenar o evitar los crímenes, que por lo demás desconocía. ${ }^{149}$ El Tribunal sostiene que los crímenes eran tan extendidos que o bien fueron secretamente ordenados o conscientemente permitidos por Yamashita. ${ }^{150}$ En ese sentido, tanto la Comisión Militar, como la Corte Suprema de EE.UU. reconocen que existe una obligación de los mandos militares de descubrir y controlar actos militares cometidos por sus tropas. ${ }^{151}$ Entre otras críticas, ${ }^{152}$ sería posible sostener que estamos frente a un caso de responsabilidad objetiva. Dicha crítica apunta principalmente a elemento conocimiento del dolo, sin perjuicio de que el sentenciador en este caso lo dio por acreditado. ${ }^{153}$ El llamado Estándar de Yamashita se encuentra posteriormente presente en varios instrumentos internacionales, ${ }^{154}$ como en los Tribunales ad-hoc para la ex Yugoslavia y Ruanda ${ }^{155} \mathrm{y}$, finalmente, se recoge en el Estatuto de la Corte Penal Internacional. ${ }^{156}$

148 Trial of General Tomoyuki Yamashita, United States Military Commission, Manila, 8.10.1945, y The Supreme Court of the United States, 04.02.1946.

${ }_{149}$ Sobre el caso, vid. Winter Etcheberry, Jaime: La responsabilidad de los superiores...(nota 143), p. 20 -

25; y Ambos, Kai: "Superior Responsibility" (nota 144), p. 807.

150 Sentencia caso Yamashita, p. 34.

${ }^{151}$ Ibid., pp. 35 y 43.

152 Vid. Winter Etcheberry, Jaime: La responsabilidad de los superiores...(nota 143), pp. 25 y ss.

153 Ibid.

154 Ibid., pp. 28 y ss.

155 Los estatutos para ambos Tribunales contemplan expresamente a la responsabilidad por el mando en términos casi idénticos. El Tribunal Internacional para la ex Yugoslavia lo hace en el artículo 7 número 3 mientras que el Tribunal Penal Internacional para Ruanda lo hace en su artículo 6 número 3. Se transcribe la norma contemplada en el Estatuto para el Tribunal Penal Internacional para la ex Yugoslavia, señalando que la única diferencia es la referencia que se hace en el primer párrafo a los artículos 2 a 5, se hace a los artículos 2 a 4 en el caso de la Corte para Ruanda, aunque ambas referencias son hechas a la totalidad de los delitos que contemplan los respectivos estatutos:

"El hecho de que cualquiera de los actos señalados en los artículos 2 a 5 del presente estatuto fuera cometido por un subordinado no releva al superior de responsabilidad criminal si sabía o tenía razones para saber que el subordinado iba a cometer dichos actos o ya los había cometido y el superior omitió en tomar las medidas necesarias y razonables para prevenir dichos actos o para castigar a los perpetradores posteriormente".

${ }^{156}$ El Estatuto de Roma contempla la figura de la Responsabilidad del Superior en su artículo 28 en los siguientes términos:

"Responsabilidad de los jefes y otros superiores

Además de otras causales de responsabilidad penal de conformidad con el presente Estatuto por crímenes de la competencia de la Corte:

1. El jefe militar o el que actúe efectivamente como jefe militar será penalmente responsable por los crímenes de la competencia de la Corte que hubieren sido cometidos por fuerzas bajo su mando y 
REJ - Revista de Estudios de la Justicia - No 17 - Año 2012

Por último, con una criticable técnica legislativa, ${ }^{157}$ es recogido en Chile en el artículo 35 de la Ley 20.357 de 18 de julio de $2009 .{ }^{158}$

Es evidente el peligro que representa esta institución de caer en la responsabilidad objetiva, de modo que ella se construye sobre tres ejes fundamentales. ${ }^{159}$ El primero es la existencia de una relación superior-subordinado. Más

control efectivo, o su autoridad y control efectivo, según sea el caso, en razón de no haber ejercido un control apropiado sobre esas fuerzas cuando:

a) Hubiere sabido o, en razón de las circunstancias del momento, hubiere debido saber que las fuerzas estaban cometiendo esos crímenes o se proponían cometerlos; y

b) No hubiere adoptado todas las medidas necesarias y razonables a su alcance para prevenir o reprimir su comisión o para poner el asunto en conocimiento de las autoridades competentes a los efectos de su investigación y enjuiciamiento.

2. En lo que respecta a las relaciones entre superior y subordinado distintas de las señaladas en el apartado a), el superior será penalmente responsable por los crímenes de la competencia de la Corte que hubieren sido cometidos por subordinados bajo su autoridad y control efectivo, en razón de no haber ejercido un control apropiado sobre esos subordinados, cuando:

a) Hubiere tenido conocimiento o deliberadamente hubiere hecho caso omiso de información que indicase claramente que los subordinados estaban cometiendo esos crímenes o se proponían cometerlos;

b) Los crímenes guardaren relación con actividades bajo su responsabilidad y control efectivo; y

c) No hubiere adoptado todas las medidas necesarias y razonables a su alcance para prevenir o reprimir su comisión o para poner el asunto en conocimiento de las autoridades competentes a los efectos de su investigación y enjuiciamiento".

${ }_{157}$ Aunque acierta en exigir el dolo como estándar, no expresa con claridad la necesidad de una relación superior-subordinado, lo que podría significar una responsabilidad por la mera capacidad de evitación.

158 "Serán sancionados como autores de los delitos previstos en esta ley las autoridades o jefes militares o quienes actúen efectivamente como tales, en su caso, que teniendo conocimiento de su comisión por otro, no la impidieren, pudiendo hacerlo.

La autoridad o jefe militar o quien actúe como tal que, no pudiendo impedir el hecho, omitiere dar aviso oportuno a la autoridad competente, será sancionado con la pena correspondiente al autor, rebajada en uno o dos grados".

${ }^{159}$ La doctrina y la jurisprudencia, en general, le reconoce a la responsabilidad por el mando estos tres elementos. (1) Relación de superior-subordinado que implique mando y control efectivo. (2) Conocimiento de que los subordinados estaban cometiendo o iban a cometer los crímenes de base. (3) El superior omite tomar las medidas necesarias para evitar dicha comisión. (Vid., Winter Etcheberry, Jaime: La responsabilidad de los superiores...(nota 143), p. 14 y, en especial, nota al pie 34). Esto está en las sentencias de la Cámara de Apelación y de la Cámara de enjuiciamiento, respectivamente, del Tribunal Penal Internacional para la ex Yugoslavia en los casos contra Kordić y el juicio contra Delalić (Mucić et al.), por sus acciones en la prisión de "Čelebici”, así también se reconoce en Blaskić. Kordić (IT-95-14/2) Appeals Chamber, 17 de Diciembre de 2004, párrafo \$ 834; Čelebici (IT-96-21) Trial Chamber, 16 de Noviembre de 1998, párrafo \346; Blaskić (IT-95-14) Appeals Chamber, 24 Julio de 2004, párrafo \484. Los mismos elementos considera Martínez: "(i) the existence of a de iure or de facto superior-subordinate relation ship of effective control; (ii) the superior knew orbad reason to know that the criminal act was about to be orhad been committed; (iii) the superior failed to take necessary steps to prevent or punish the offences", es decir, "(i)la existencia de una relación superior subordinado de control efectivo, ya sea de facto o de iure; (ii) el superior sabía o debía saber que el acto criminal iba a ser o había sido cometido; (iii) el superior omite tomar las medidas necesarias para prevenir o castigar el ilícito". Se diferencia con la formulación del Tribunal Penal Internacional para la ex Yugoslavia únicamente en que agrega que la relación superior-subordinado puede ser de facto. 
allá de la discusión sobre los superiores de facto y del hecho que se acepte que los superiores no sólo sean militares, lo relevante de este elemento es que reconoce que la relación debe darse, aunque sea de facto, al interior de una organización compleja. En este requisito está la fundamentación primaria de la posición de garante. Ello se concretiza en la necesidad de que el individuo tenga el mando (o autoridad) y el control efectivo sobre los subordinados. Esto significa que por un lado, debe tener la capacidad fáctica de impedir el hecho y, además, que esa capacidad fáctica debe venir avalada por su rol institucional, es decir, que se reconozca dicha posición al interior de la organización, aunque sea de facto. ${ }^{160} \mathrm{Un}$ segundo elemento, y tal vez el más problemático, tiene que ver con el conocimiento del superior. En el Estatuto de Roma se establece que la responsabilidad del superior si este hubiere sabido o hubiere debido saber (o, en el caso de los superiores civiles, hubiere tenido conocimiento o deliberadamente hubiere hecho caso omiso de información que indicase claramente) de los crímenes que sus subordinados estaban cometiendo o se proponían cometer los crímenes. El estándar de "haber sabido" no presenta mayores problemas y es simplemente el elemento de conocimiento del dolo. En cambio los mayores problemas se presentan con el haber debido saber. Hay posiciones que lo presentan como una forma de responsabilidad objetiva, mientras que otros sostienen que sería una forma de responsabilidad culposa. ${ }^{161}$ Posiblemente quienes lo han observado con más profundidad han llegado a la conclusión que existe un conocimiento constructivo que es un tipo de negligencia, pero extrema, similar a la culpa lata en Derecho civil y, como ésta, equivalente al dolo. Estas posiciones implican la imposibilidad de conectar en coautoría o participación en el hecho principal con la omisión del superior, debido a la necesaria convergencia intencional en el hecho ajeno, es decir, no hay cómplices ni coautores culposos. Esto obliga a señalar que se trataría de un delito distinto. ${ }^{162}$ En cambio, también es posible señalar que el estándar constituye dolo eventual. Si existe una decisión deliberada de quedar en la ignorancia, esto implica que era de conocimiento del superior la probabilidad, de acuerdo con las circunstancias, de que el hecho llegara a ocurrir y decidió de todos modos ignorarlo. ${ }^{163}$ Esto implicaría excluir casos donde efectivamente el conocimiento no se haya adquirido por mera negligencia al actuar. Esto no es tan problemático en la regulación chilena, toda vez que no se crea un delito especial y el único estándar el dolo. El último elemento de la responsabilidad del superior es no haber evitado el becho o intentado evitarlo, que representa propiamente la omisión del superior.

Similar regulación se encuentra en el Código Penal (CP) en el inciso segundo del artículo $150 \mathrm{~A}$, que al referirse a las torturas y apremios ilegítimos señala que "[l]as mismas penas, disminuidas en un grado, se aplicarán al empleado

\footnotetext{
Martínez, Jenny S.: "Understanding Mens Rea in Command Responsibility, From Yamashita to Blaškić and Beyond”, Oxford Journal of International Criminal Justice 3, 2007, p. 642.

160 Vid. Winter Etcheberry, Jaime: La responsabilidad de los superiores... (nota 143), pp. 46 y siguientes. En especial, pp. 49-51.

161 Una completa relación de las posiciones dogmáticas en Ibid., pp. 162 y ss.

162 Ambos, Kai: Der Allgemeine Teil, 2002 (nota 146), pp. 667 y 668.

163 Winter Etcheberry, Jaime: La responsabilidad de los superiores (nota 143), pp. 179 y ss.
} 
público que, conociendo la ocurrencia de las conductas tipificadas en el inciso precedente, no las impidiere o hiciere cesar, teniendo la facultad o autoridad necesaria para ello".

En estos casos la discusión sobre el fundamento de la posición de garante, que debe ser extrapenal, se ha diluido por el hecho que los delitos se encuentran tipificados y, en el caso de los superiores militares, debido a que se entiende que los deberes militares funcionan sin problema como fuente.

Más problemática es la justificación en el caso de la omisión de evitar el hecho en las empresas (por delitos que no son crímenes de Derecho penal internacional), es decir, la creación de una posición de garante general de quienes administran las empresas. En estos casos, no existe una disposición penal que haga punible la conducta del superior (o en este caso dirección de la empresa). Por ello, se ha visto aquí una vulneración del llamado principio de autonomía o responsabilidad personal, derivado del principio de culpabilidad, que establece que nadie puede ser hecho responsable por el comportamiento de otro. ${ }^{164}$

Hasta ahora la fundamentación de tal posición de garante ha sido objeto de distintos intentos de justificación. ${ }^{165}$ Algunos simplemente la dan por supuesta o la derivan de la existencia de una fuente de peligro sin profundizar en el asunto. ${ }^{166}$ Por lo ya dicho, difícilmente una persona que pueda autodeterminarse pueda ser considerada una fuente de peligro en sentido jurídico penal. ${ }^{167}$ En caso de que la fuente de peligro no fuera propiamente un subordinado, sino que un objeto -por ejemplo, un producto- el asunto tampoco es claro. Existen en el mundo innumerables fuentes de peligros e innumerables personas que tienen la capacidad

\footnotetext{
164 Tiedemann, Klaus: Wirstschaftsstrafrecht, 2007 p. 79.

165 Aquí se tratan principalmente casos en que se considera a la empresa, sus empleados o productos como fuentes de peligro. Desde ya cabe descartar aquellos que se basan en hacer responsable a quien dirige la empresa por los bienes jurídicos que la actividad pone en peligro. Estas explicaciones trasladan la obligación, en la clásica clasificación de Kaufmann (Kaufmann, Armin: La Dogmática de los Delitos de Omisión, 2006, pp. 289 y 290), de controlar una fuente de peligro a la protección de bienes jurídicos. Así, hay una tendencia a aceptar aquellos casos en que se desarrolla una actividad peligrosa, como construcciones, extracciones, talleres mecánicos, ferrocarriles, etc. (vid. Tiedemann, Klaus: Wirstschaftsstrafrecht [nota 164], p. 79). En cualquier caso se encuentra aquí con otro problema. Si no queremos sólo estar frente a un fraude de etiquetas -considerando la dificultad de llevar a la práctica la distinción-, es necesario determinar los bienes jurídicos protegidos, lo cual fija un ámbito de responsabilidad limitado de quien dirige al ente. Sin perjuicio de ello, fracasan también las teorías que se basan en la protección de bienes jurídicos de la propia empresa, porque los que se dañan suelen ser ajenos; y las que se basan en el monopolio de la decisión sobre el bien jurídico, que se aplican más bien a órganos del Estado y no a empresas, que en ningún caso tienen monopolio sobre la decisión de bienes jurídicos ajenos. (Cfr. Rotsch, Thomas: Individuelle Haftung in Großunternehmen [nota 140], pp. 187 a 190). Para ver panoramas generales sobre la discusión, el ya referido Ibid., pp. 187-206; con referencias a la jurisprudencia alemana, Schünemann, Bernd: Unternehmenskriminalität... (nota 96), pp. 62-110. Vid. también Tiedemann, Klaus: Wirstschaftsstrafrecht(nota 164), pp. 78-82.

$166 \mathrm{Al}$ respecto, Schünemann, Bernd: Unternehmenskriminalität... (nota 96), pp. 77 y 78 ; y 83.

167 Ibid., p. 78.
} 
Winter - Situaciones actuales en la frontera del principio de culpabilidad

de evitar que ese peligro se concrete. Esto no significa que estas personas tengan una posición de garante general respecto de estos peligros. A lo más, esto podrá ser una mera omisión de socorro, pero no una realización de una comisión por omisión. Así, la posición de garante debe estar fundada más allá de la mera capacidad de evitación de la concreción del peligro.

A partir de esto, se ha sostenido que si se crea una fuente de peligro le incumbe a la persona un especial deber de cuidado cuando un peligro específico se deriva de ella y no se puede impedir -suficientemente- mediante controles sociales. Igualmente cuando los potenciales afectados no están en la posición de tomar las medidas de protección. ${ }^{168}$ Esto se puede fundamentar, por ejemplo, simplemente entendiendo que quien obtiene $-\mathrm{O}$ se tolera que obtenga- un beneficio económico por la actividad debe también preocuparse de evitar los peligros que se derivan de dicha actividad. ${ }^{169}$ Por supuesto, esta teoría limita con aquellas organizaciones cuyo enfoque prioritario no es la obtención de beneficios económicos. ${ }^{170}$ Otra posición es considerar que la organización en sí misma representa una especial fuente de peligro, en virtud de las especiales características que implican que es algo distinto a sus meros miembros. ${ }^{171}$ Una posición de este tipo depende de la delegación para justificar la imposición de la obligación de cuidado a quien no creó la organización y es problemática al no internalizar la complejidad de la organización actual de la empresa, que separa las competencias de los distintos miembros. Así, no se sigue de la argumentación que los superiores tengan la obligación jurídica de vigilar la conducta de sus subordinados, en el sentido de evitar la comisión de ilícitos. ${ }^{172}$

Posiblemente la justificación más conocida, desde que fuera sostenida por el Tribunal Supremo Alemán en el caso del Letherspray, ${ }^{173}$ sea la de la injerencia. ${ }^{174}$

\footnotetext{
168 Se refiere a esta posición, Rotsch, Thomas: Individuelle Haftung in Großunternehmen(nota 140), p. 195. Stratenwerth y Kuhlen aceptan esto en el caso de la obligación de retirada en la responsabilidad por el producto, en base al dominio sobre la fuente de peligro, pero sosteniendo que lo normal es que el único que conoce el riesgo y que puede hacer el retiro a través de la organización. Cfr. Stratenwerth, Gunther y Kuhlen, Lothar: Strafrecht... (nota 142), p. 288.

169 Rotsch cita a Stratenwerth, sin embargo, como también advierte Rotsch, dicha posición es posteriormente morigerada y en la última edición de su manual con Kuhlen la idea principal es la de dominio de la actividad. Vid., Rotsch, Thomas: Individuelle Haftung in Großunternehmen (nota 140), p. 196; y Stratenwerth, Gunther y Kuhlen, Lothar: Strafrecht... (nota 142), pp. 286 a 288.

170 Rotsch, Thomas: Individuelle Haftung in Großunternebmen (nota 140), p. 202.

171 Ya explicado en el capítulo sobre la responsabilidad penal de las personas jurídicas.

172 Cfr. Rotsch, Thomas: Individuelle Haftung in Großunternehmen (nota 140), pp. 203-206.

173 BGHSt, 37, 106, de 06.071990.

174 Muy cerca a la idea de la injerencia están otras justificaciones que se basan en ciertas obligaciones anteriores del tráfico comercial. Destaca entre ellas la de Schünemann que para fundar la obligación de advertencia (o de retirada, según la sentencia del Letherspray) cuando un producto, sin que se haya descubierto previamente, resulta ser defectuoso, recurre a la obligación civil previa de "observación del producto", es decir, la obligación de la empresa no cesa con la puesta a la venta del producto, sino que tiene la obligación de preocuparse por él posteriormente. Es evidente que tal posición no tiene el alcance amplio que se pretende de la posición de garante del superior de
} 
Esto significa que quien ha creado un peligro específico debe hacerse responsable de evitar sus consecuencias. ${ }^{175}$ Un primer problema es que la integración de las empresas es dinámica, de modo que quien ocupa el lugar de gerente en un momento determinado puede no ser el mismo que posteriormente conoce del problema y debe reaccionar ante éste. Sin perjuicio de ello, es posible contraargumentar que con la asunción de una posición en la empresa, también se asumen las responsabilidades de quien detentaba antes la posición.

El problema fundamental, sin embargo, es si la posición de garante por injerencia sólo puede derivarse de una infracción de deber previa, cuando la conducta ex ante pudo ser considerada peligrosa o, simplemente, fundar la injerencia en la peligrosidad determinada ex post. ${ }^{176}$ Queda descartada la consideración de una infracción de deber determinada ex post, considerando que la creación de deberes debe motivar a su destinatario, de modo que pueda comportarse de acuerdo con la norma, de este modo si la peligrosidad sólo se puede determinar ex post, no hay una infracción de deber. ${ }^{177}$ Cuál de las dos posiciones aceptables es la correcta todavía se discute, ${ }^{178}$ pero pareciera que la primera -infracción de deber previa- es la más adecuada. Muchas de nuestras conductas crean peligros legítimos o simplemente desconocidos y esto no significa que seamos penalmente responsables por no evitar que dichos peligros se concreten. ${ }^{179}$

Como se ve, aunque la tendencia mayoritaria es aceptar una posición de garante de los superiores en las empresas, su concreta extensión y fundamentación, acorde al principio de culpabilidad, es todavía objeto de discusión. Esto ha provocado que se hayan creado criterios secundarios que limitan dicha imputación, como, por ejemplo, la noción de las conductas neutrales, ${ }^{180}$ la delegación y la división del trabajo ${ }^{181}$ y el principio de confianza. ${ }^{182}$

una empresa y queda limitada sólo a casos de responsabilidad por el producto. (cfr. Schünemann, Bernd: "Responsabilidad penal..." [nota 137], p. 33).

175 Por ejemplo, vid. Rotsch, Thomas: Individuelle Haftung in Großunternebmen (nota 140), p. 190.

176 Ibid., pp. 191 y 192.

177 Kuhlen, Lothar: "Strafhaftung bei unterlassenem Rückruf gesundheitsgefährdender Produkte", NStZ 12, 1990, p. 568; Rotsch, Thomas: Individuelle Haftung in Großunternehmen (nota 140), p. 192.

178 Ibid., p. 190 y 191.

${ }^{179}$ En el mismo sentido, Kuhlen, Lothar: "Strafhaftung..." (nota 177), p. 568.

${ }^{180}$ Las conductas neutrales son casos en que formalmente los actos deberían ser punibles, pero se entiende que por ser cotidianas o triviales, es posible considerarlos socialmente adecuadas. El típico caso es el del funcionario bancario que dentro de sus obligaciones ayuda a un cliente, sabiendo que usará la ayuda para cometer un delito. Vid. al respecto, Rotsch, Thomas: "Einheitstäterschaft"... (nota 139), pp. 399 y ss.

${ }^{181}$ La idea de la delegación y división del trabajo tienen que ver con la definición de ámbitos de organización. Según Feijoo (Feijoo Sánchez, Bernardo: “Autoría y participación en organizaciones empresariales complejas", en, del mismo, Cuestiones actuales de Derecho penal económico, 2009, pp. 1-48), por ejemplo, la imputación primaria se hace al colectivo u organización (pp. 18 y ss.) y sólo luego se puede determinar quién tenía materialmente la responsabilidad por la evitación del hecho respectivo, es decir, quien tenía el asunto específico dentro de su ámbito de competencia, lo que se obtiene según los principios de delegación y división del trabajo (pp. 20-23). En caso de 
Winter - Situaciones actuales en la frontera del principio de culpabilidad

Ahora bien, el problema de la posición de garante por conductas de terceros ha tenido también eco en ámbitos ajenos a las organizaciones. Por ejemplo, donde el límite se ha desdibujado es en el Proyecto de Ley que "Fortalece el resguardo del orden público", llamado también "Ley Hinzpeter". ${ }^{183}$ En el que sería el nuevo art. 269 del CP se busca sancionar a quienes en el contexto de desórdenes públicos u otros actos de fuerza o violencia realizan conductas como interrupción de servicios, "invasión", "ocupación" y "saqueo", interrumpir el tránsito, atentar contra la autoridad, emplear armas o dañar la propiedad. ${ }^{184}$

En su inciso final establece que "se aplicará la pena de presidio menor en su grado medio a quienes hubieren incitado, promovido o fomentado los desórdenes u otro acto de fuerza o violencia que importen la realización de alguno de los hechos señalados en el inciso primero, siempre que la ocurrencia de los mismos haya sido prevista por aquéllos".

Esta disposición está destinada conocidamente a criminalizar a aquellos que organizan marchas, protestas y tomas. Como puede verse, hay una pluralidad de verbos rectores: "incitar", "promover" y "fomentar". Es evidente que el uso de estos verbos pretende ser algo más amplio que una inducción directa como se

existir corresponsabilidad, entra en juego el principio de confianza, es decir, hasta qué punto se puede confiar en la actuación del otro (pp. 23-27).

182 Puppe lo explica a propósito de las intervenciones médicas. El principio de confianza tiene su origen en el ámbito del tráfico rodado, donde se puede esperar que los demás partícipes van a respetar las reglas. Esto, considera él, es aplicable a todos los casos de división del trabajo. El principio regiría de forma plena en relaciones de igualdad, pero sólo limitadamente en relaciones de subordinación, donde se mantienen las obligaciones de supervisión, como del médico respecto de la enfermera o del joven en formación. Vid. Puppe, Ingeborg: "División del trabajo y de la responsabilidad en la actuación médica", InDret 4, 2006, pp. 3 y 4.

183 Boletín 7975-25 Cámara de Diputados.

184 Artículo 269: Serán castigados con la pena de presidio menor en su grado medio quienes participen en desórdenes o cualquier otro acto de fuerza o violencia que importen la realización de alguno de los siguientes hechos:

1.- Paralizar o interrumpir algún servicio público, tales como los hospitalarios, los de emergencia y los de electricidad, combustibles, agua potable, comunicaciones o transporte;

2.- Invadir, ocupar o saquear viviendas, oficinas, establecimientos comerciales, industriales, educacionales, religiosos o cualquiera otro, sean privados, fiscales o municipales;

3.- Impedir o alterar la libre circulación de las personas o vehículos por puentes, calles, caminos u otros bienes de uso público semejantes;

4.- Atentar en contra de la autoridad o sus agentes en los términos de los artículos 261 o 262 o de alguna de las formas previstas en los artículos 416, 416 bis, 416 ter y 417 del Código de Justicia Militar o en los artículos 17, 17 bis, 17 ter y 17 quáter del Decreto Ley $N^{\circ} 2.460$ de 1979, o en los artículos 15 A, 15 B, 15 C y 15 D del Decreto Ley N 2.859 de 1979, según corresponda;

5.- Emplear armas de fuego, cortantes o punzantes, artefactos o elementos explosivos, incendiarios o químicos u otros capaces de producir daños a las personas o a la propiedad; o,

6.- Causar daños a la propiedad ajena, sea pública, municipal o particular.

La pena establecida en el inciso precedente se impondrá sin perjuicio de la que, en su caso, corresponda aplicar además a los responsables por su intervención en los daños, incendio, atentados, robo, infracciones a la Ley $\mathrm{N}^{\circ} 17.798$ sobre Control de Armas y, en general, otros delitos que cometan con motivo o con ocasión de los desórdenes o de los actos de fuerza o violencia. 
establece en el artículo $15 \mathrm{~N}^{\circ} 2$ del $\mathrm{CP}$, posiblemente cercana a la idea de apología ${ }^{185}$ pero su verdadero alcance no está claro. En general, se puede decir que no requiere el nivel de determinación de la inducción ni en cuanto a los hechos, ni en cuanto a quienes se espera que realicen de manera inmediata las conductas, ni quienes serían las víctimas. Así mismo, tampoco está determinado qué son desórdenes públicos ni actos de fuerza o violencia. Es posible, por ejemplo, que una marcha no autorizada o una marcha autorizada, pero posteriormente disuelta por la fuerza pública sea considerada un desorden público. Así entonces, por la mera promoción de estos hechos quien lo hace será responsable, por ejemplo, por atentados a carabineros que hagan otros partícipes en la marcha. Aquí no es necesario que el individuo incite, promueva o fomente los hechos, sino que simplemente hayan sido "previsibles". Es evidente que hoy en día es posible prever la producción de delitos en actos públicos.

No existe ninguna justificación a esta disposición que crea la responsabilidad por hechos de terceros. Si revisamos los ámbitos en que se puede defender la posición de garante en los casos anteriores, vemos que ninguno de ellos se justifica aquí. En primer lugar, parece relevante que exista una organización. Sólo dentro de su estructura se fundamenta la posición de garante de sus miembros. Pero incluso cuando en estos casos existieran organizaciones -por ejemplo, un centro de estudiantes o un sindicato-, estos no tienen las características propias de complejidad y estructura interna jerarquizada que permiten la imputación por hechos de terceros. Normalmente no se alcancen niveles de complejidad interna suficientes para diferenciarlos de sus miembros. Aunque tengan "bases" numerosas, la estructura interna suele permitir sólo tareas básicas. De esto se sigue lo evidente, que el individuo no tiene ni mando institucionalmente reconocido ni control fáctico sobre los individuos, de modo que no puede impedir la realización de los hechos. Por otra parte, no es posible sostener que el peligro sea distinto en caso de actividades autorizadas y actividades no autorizadas, de modo que no se justifica una creación de una posición de garante especial basada en los casos de actividades ilícitas. En definitiva, es evidente que no es más que una limitación ilegítima del derecho de reunión y una vulneración al principio de culpabilidad.

\footnotetext{
185 La llamada apología, que no se encuentra reflejada en el sistema chileno, tiende a tomar dos formas diferentes. Una consiste en defender un crimen realizado o a su autor. En general, esta clase de tipos penales suelen ser criticadas en cuanto a su legitimidad y posiblemente la única forma de justificarlo sea entendiendo que implican una incitación indirecta (vid. Creus, Carlos: Derecho Penal, Parte especial, 1998, p. 128). La segunda forma está vinculada efectivamente con la incitación general a la comisión de un delito específico. Se ha considerado que dicha incitación debe ser directa (vid. Bustos Ramírez, Juan y Hormazábal Malarée, Hernán, Lecciones de Derecho Penal, vol. II, 1999, p. 263 y 264). En estos casos, que serían similares a la norma en análisis, existe la diferencia de que los hechos no deben ser sólo previsibles, sino directamente buscados. Por lo demás, es claro que no se justifica un trato diferenciado para este tipo de delitos y no una norma general o referida a crímenes particularmente graves.
} 
Winter - Situaciones actuales en la frontera del principio de culpabilidad

\section{Medidas de seguridad complementarias a la pena}

Una importante excepción al principio de culpabilidad en nuestro sistema está constituida por las medidas de seguridad. ${ }^{186}$ Nuestro Derecho penal es un Derecho de doble vía. ${ }^{187}$ La pena se basa en la culpabilidad del sujeto, mientras que la medida de seguridad se basa en su peligrosidad. ${ }^{188} \mathrm{El}$ caso más conocido es el demente que no puede ser objeto de imputación de culpabilidad (por ausencia de imputabilidad), de modo que se le aplica una medida similar. Al momento de dictación del CP la influencia de la escuela positivista, que le da impulso a la consagración de medidas de seguridad, no existía todavía. En virtud de ello, las medidas de seguridad no se encuentran en el CP. En el Código Procesal Penal (CPP) sí se consagran en el Título VII del Libro Cuarto, artículos 445 a 465, mientras que su ejecución está establecida en el párrafo $4^{\circ}$ del Título VIII del Libro Cuarto, artículos 481 y 482.

A pesar del relativo acuerdo que existe en su necesidad dentro del sistema, es claro que la existencia de este tipo de reacción penal representa un riesgo relevante dentro del mismo. A diferencia de un juicio retrospectivo objetivo que representa la culpabilidad, el juicio que se hace respecto a la peligrosidad es prospectivo y abre una peligrosa puerta a la arbitrariedad. Este riesgo no sólo tiene que ver con la imposición de la reacción, sino que también con su duración. En virtud de ello, por ejemplo, la regulación de nuestro CPP exige que, además del juicio de peligrosidad, se cumplan todos los requisitos del injusto, esto es, que existiera una conducta típica y antijurídica, renunciándose sólo al requisito de la culpabilidad, que se reemplaza por un juicio de peligrosidad. ${ }^{189}$ Además, su duración está limitada por la de la pena que le correspondería al hecho de haber sido un delito. ${ }^{190}$

Sin embargo, además de las medidas de seguridad como una vía alternativa a la pena existe teóricamente la posibilidad de que se establezcan como copulativas. Es decir, que la pena se complemente con una medida de seguridad. A grandes rasgos, esto significa que, por ejemplo, luego de cumplida una pena privativa de libertad, sería posible que el sujeto siga en el encierro si existe un juicio de peligrosidad desfavorable en su contra.

\footnotetext{
186 Así lo considera, por ejemplo, Garrido Montt, Mario: Derecho Penal, t. I (nota 1), p. 35.

187 Vid., por ejemplo, Roxin, Claus: Strafrecht (nota 13), p. 3.

188 Ibid., p. 2.

189 Artículo 455 del CPP: Procedencia de la aplicación de medidas de seguridad. En el proceso penal sólo podrá aplicarse una medida de seguridad al enajenado mental que hubiere realizado un hecho típico y antijurídico y siempre que existieren antecedentes calificados que permitieren presumir que atentará contra sí mismo o contra otras personas.

190 Artículo 481 inciso primero CPP: Duración y control de las medidas de seguridad. Las medidas de seguridad impuestas al enajenado mental sólo podrán durar mientras subsistieren las condiciones que las hubieren hecho necesarias, y en ningún caso podrán extenderse más allá de la sanción restrictiva o privativa de libertad que hubiere podido imponérsele o del tiempo que correspondiere a la pena mínima probable, el que será señalado por el tribunal en su fallo.
} 
Esto que suena completamente ajeno al Derecho chileno está presente con claridad en códigos penales extranjeros. Así, por ejemplo, la prensa informó que a Anders Behring Breivik, quien en julio de 2011 asesinó a 77 personas en Noruega, se le impuso una pena de 21 años, pero con la posibilidad de ser renovada si persiste la peligrosidad del individuo una vez cumplida la pena. ${ }^{191}$ Esta posibilidad se contempla en la sección 39 c) del Código Penal Noruego. ${ }^{192}$ Igualmente los párrafos 66 y siguientes del Código Penal Alemán (StGB) regulan esta institución. La normativa es extensa y compleja, lo que demuestra la reticencia del legislador a su aplicación.

En la legislación chilena es posible encontrar una tendencia hacia medidas de seguridad complementarias en el caso de quienes cometen delitos sexuales contra menores. Así, el artículo 372 CP los condena a la sujeción a la vigilancia de la autoridad por el plazo de 10 años, consistente en informar a Carabineros cada tres meses su domicilio actual. ${ }^{193}$ Es evidente que más que una sanción se constituye como una forma de controlar al sujeto, lo que se condice con la noción general que existe de que los pederastas tenderían a la reincidencia. Similar inclinación se encuentra en los incisos segundos del artículo 371 y del propio 372, en que además de la pena que se le impone al individuo, se establece una inhabilitación para cargos, oficios o profesiones que tengan que ver con la educación o con contacto con menores de edad. ${ }^{194}$ En estos casos, más pareciera que la idea que hay detrás no es el merecimiento de esa pena específica, sino que de la peligrosidad que representa el individuo en relación con los menores. Que existan límites temporales no obsta a lo señalado, considerando que la duración máxima de la pena ha tendido a ser una forma de limitación de las medidas de seguridad.

${ }^{191}$ EFE, "Sentencian a Anders Behring Breivik a 21 años de cárcel por atentados de Noruega", La Tercera, 24.08.2012.

192 Sección 39 c, versión en inglés disponible en http://www.ub.uio.no/ujur/ulovdata/lov19020522-010-eng.pdf (consultado el 15.10.2012).

193 Artículo 372 del CP: Los comprendidos en el artículo anterior y cualesquiera otros condenados por la comisión de los delitos previstos en los dos párrafos precedentes en contra de un menor de edad, serán también condenados a las penas de interdicción del derecho de ejercer la guarda y ser oídos como parientes en los casos que la ley designa, y de sujeción a la vigilancia de la autoridad durante los diez años siguientes al cumplimiento de la pena principal. Esta sujeción consistirá en informar a Carabineros cada tres meses su domicilio actual. El incumplimiento de esta obligación configurará la conducta establecida en el artículo $496 \mathrm{~N}^{\circ} 1$ de este Código.

194 Artículo 371 del CP: Los ascendientes, guardadores, maestros y cualesquiera personas que con abuso de autoridad o encargo, cooperaren como cómplices a la perpetración de los delitos comprendidos en los dos párrafos precedentes, serán penados como autores.

Los maestros o encargados en cualquier manera de la educación o dirección de la juventud, serán además condenados a inhabilitación especial perpetua para el cargo u oficio.

Artículo 372 inciso segundo del CP: Asimismo, el tribunal condenará a las personas comprendidas en el artículo precedente a la pena de inhabilitación absoluta temporal para cargos, oficios o profesiones ejercidos en ámbitos educacionales o que involucren una relación directa y habitual con personas menores de edad, en cualquiera de sus grados. 
Winter - Situaciones actuales en la frontera del principio de culpabilidad

Aunque no representan un tema relevante de discusión para la dogmática chilena, fueron en su momento promovidas por Etcheberry en los siguientes términos:

Sin embargo, es también innegable que hay casos en los cuales (en gran medida por las condiciones lamentables en que se cumplen las penas de encierro), la finalidad de reforma o reinserción no se logra, y la peligrosidad del condenado puesto en libertad, para sí mismo y para la sociedad en general, subsiste aún. ¿Qué hacer en tales casos? Esta finalidad se consigue a través de las medidas de seguridad, que lamentablemente no han sido consideradas en absoluto en el proyecto del Foro (pese a que el Código Procesal Penal contempla expresamente un procedimiento para la imposición exclusiva de medidas de seguridad). Cuando el cumplimiento de la pena se ha revelado incapaz de evitar la recaída en el delito (reincidentes, delincuentes habituales o por tendencia) o se muestra inútil para motivar la conducta de los sujetos (enajenados o semienajenados peligrosos, enviciados adictos), la medida de seguridad, que debe señalarse expresamente que no es una pena debe venir a añadirse a la pena o a sustituirla por completo, para lograr, si es posible, la misma finalidad que la pena es incapaz de obtener. ${ }^{195}$

El trabajo que de manera más directa en nuestro medio analiza el asunto es el de Maldonado. ${ }^{196} \mathrm{Al}$ respecto, constata ${ }^{197}$ que la aceptación de ambas reacciones en forma copulativa sería mayoritaria en la doctrina. ${ }^{198}$ Para su análisis recoge en varios grupos las justificaciones que existen para la aplicación copulativa de penas y medidas de seguridad. ${ }^{199}$

El primer grupo considera que la justificación de cada una por separado es suficiente: la pena tiene su fundamento y limitación en la culpabilidad y persigue fines preventivo-generales o retributivos, caracterizándose por ser la mera imposición de un mal; mientras que la medida de seguridad se fundamenta en la

195 Etcheberry, Alfredo: "Reflexiones sobre Política Criminal. Intervención del Profesor Alfredo Etcheberry en la Ceremonia de su Investidura como Doctor Honoris Causa por la Universidad de Talca”, Politica Criminal 7, 2009, p. 241.

196 Maldonado Fuentes, Francisco: “¿Se puede justificar la aplicación copulativa de penas y medidas de seguridad? Estado actual de las posiciones doctrinales que buscan dicho objeto", Política Criminal $12,2011$.

197 Ibid., p. 388.

198 Semejante constatación no tiene una verdadera equivalencia en la doctrina chilena, en la cual la discusión está más bien ausente, centrándose, en realidad, en la discusión sobre medidas de seguridad predelictuales y posdelictuales. Vid., por ejemplo, Garrido Montt, Mario: Derecho Penal, t. I (nota 1), pp. 35 y 36; y Politoff L., Sergio, Matus A., Jean Pierre y Ramírez G., María Cecilia: Lecciones de Derecho Penal. Parte General (nota 4), p. 79.

${ }^{199}$ Maldonado Fuentes, Francisco: “¿Se puede justificar...” (nota 196), p. 389. 
peligrosidad y persigue finalidades de prevención especial. ${ }^{200}$ Contra esta postura la objeción esencial es que la conceptualización del sujeto en ambos casos es diversa. En el caso de la pena, se entiende que es un individuo que puede motivarse por la norma, mientras que en el caso de la medida de seguridad no se le reconoce esa capacidad al individuo. ${ }^{201}$ Asimismo, se produce un problema al no reconocerse las virtudes limitativas de cada uno de los sistemas: puede ser que uno requiera una intervención más extensa y con eso afecte los fines del que requiere una menos intensa. ${ }^{202}$ Esto demuestra que los dos subsistemas no pueden realmente funcionar de forma absolutamente paralela, sino que se afectan entre sí. ${ }^{203}$ Esto es particularmente evidente cuando se considera que, por ejemplo, en el Derecho Chileno, la duración de la medida de seguridad se limita por la duración de la pena por un injusto equivalente. ${ }^{204}$

El segundo grupo justificaría la doble reacción en un interés preponderante en la prevención del delito. En resumen, la prevención del delito pesaría más que sus derechos individuales. ${ }^{205}$ Un primer y evidente problema de esta justificación está dado por la ausencia de un criterio adecuado para realizar la ponderación, ${ }^{206}$ esto significa que sin un criterio de ponderación adecuado cualquier uso abusivo de las medidas de seguridad podría justificarse. Más aún, existiendo un límite de la pena en la culpabilidad, pretender que ese límite se vea superado por, precisamente el elemento que pretende limitar, la extensión de la prevención, ${ }^{207}$ significa virtualmente renunciar a la culpabilidad como límite. ${ }^{208}$

El siguiente grupo intenta ver algún grado de merecimiento en la imposición de la medida de seguridad. La inseguridad que crea el sujeto es atribuible al propio individuo, por lo que debe asumir sus consecuencias. ${ }^{209}$ En último término, llevar a cabo este juicio implica en la práctica desconocer el carácter de ciudadano del individuo, desconociéndose su ámbito de libertad. En el fondo lo que se está sancionando es su ánimo contrario a derecho, lo que constituye un derecho penal de autor. ${ }^{210}$

$\mathrm{Al}$ respecto es posible señalar lo siguiente. En primer lugar, la insuficiencia de los fundamentos actualmente existentes no implica que no puedan encontrarse fundamentos adecuados en el futuro, de modo que es una posibilidad todavía

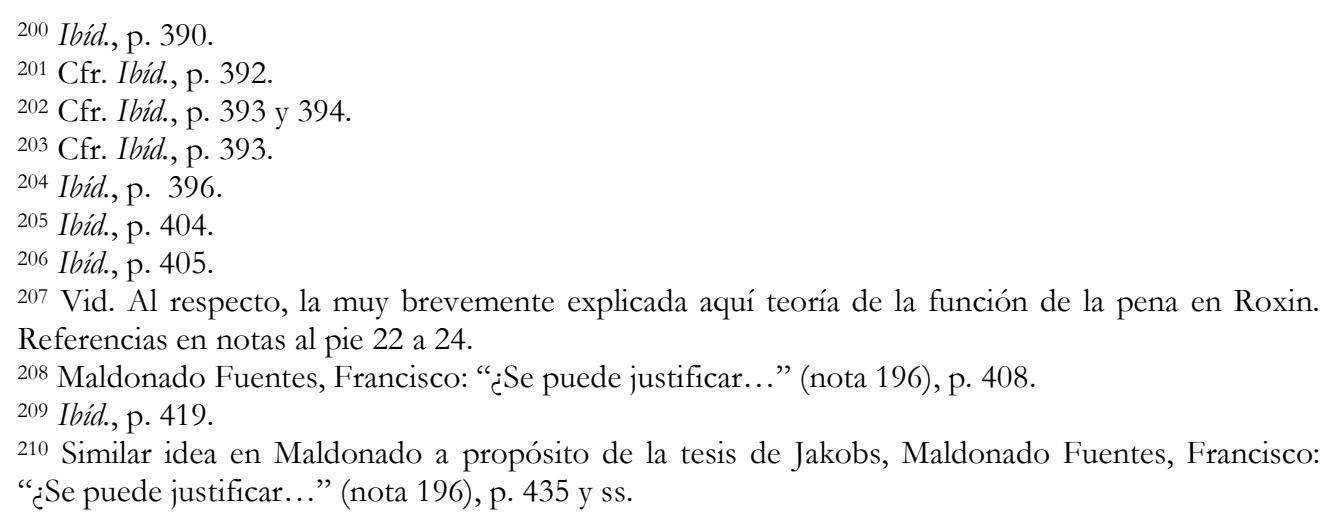


Winter - Situaciones actuales en la frontera del principio de culpabilidad

latente. En segundo lugar, conviene entonces fijar algunos límites que no debiera poder superar una formulación teórica. Así, su establecimiento sólo se podría justificar mediante su inclusión en un sistema penal más racional, en que la medida de las penas se redujera y sólo excepcionalmente se impusieran las medidas de seguridad copulativas, en casos particularmente graves. Así, por ejemplo, la propuesta de Etcheberry se enmarcaba en un sistema que proscribía las penas perpetuas y de muerte. ${ }^{211}$ En tercer lugar, el estándar para definir la imposición, revisión y duración de la medida de seguridad poscumplimiento tiene que ser objeto de un debate serio, a efecto de que se definan límites legítimos que reduzcan al mínimo el ámbito de la arbitrariedad. Esto implica, necesariamente, que debe poder diagnosticarse con una alta probabilidad la potencial futura comisión de un ilícito relativamente determinado. Si no se consideran estos presupuestos, no podría nunca justificarse la medida.

\section{Ley de responsabilidad penal adolescente}

La Ley 20.084 de Responsabilidad Penal Adolescente (LRPA) comenzó a regir en Chile con fecha 8 de junio de 2007. En ella se establece un régimen general especial para los menores de 18 y mayores de 14 años que realicen conductas típicas y antijurídicas. El efecto más evidente de este nuevo régimen se da en el ámbito de la reacción penal. ${ }^{212}$ Así, se establece que, siguiendo a las normas de la Convención sobre los Derechos del Niño, ${ }^{213}$ la responsabilidad penal de los adolescentes debe basarse en los siguientes ejes: la respuesta penal debe ser cualitativamente distinta de la de los adultos, considerándose alternativas al proceso y sanción; la respuesta penal debe ser cuantitativamente menor; garantías en la ejecución de la pena; y la fijación de una edad bajo la cual no habrá pena alguna (esta última, corresponde en realidad a un problema de imputación). ${ }^{214}$

A esto subyace la pregunta del porqué del régimen especial. En primer término, esto se vincula con la especial vulnerabilidad del menor en un contexto carcelario, pero, además, la idea de culpabilidad está relativizada. En ese contexto, ha señalado Hernández que: "La diferenciación en términos de relativa moderación o benignidad viene impuesta en consideración a las peculiaridades del agente. No obstante aceptarse la posibilidad conceptual y práctica de una

\footnotetext{
211 Etcheberry, Alfredo: "Reflexiones..." (nota 195), pp. 240 y 241.

212 Hernández Basualto, Héctor: "El nuevo Derecho penal adolescente y la necesaria revisión de su "teoría del delito"”, Revista de Derecho 2, 2007, p. 197.

213 Berríos, Gonzalo: "La ley de responsabilidad penal del adolescente como sistema de justicia: análisis y propuestas", Política Criminal 11, 2011, pp. 165. Expresa referencia a esto se hace en el Mensaje del proyecto de Ley, vid. Historia de la Ley 20.084, p. 5.

214 Couso Salas, Jaime: "La política criminal para adolescentes y la Ley 20.084", Justicia y Derechos del Niño 11, 2009, p. 220. En un sentido similar, Berríos identifica los objetivos de la Ley como la desjudicialización y alternativas a la pena; preferencia de sanciones no penales; legalidad, excepcionalidad y brevedad de la sanción privativa de libertad; y favorecer la conducta conforme a derecho, promover la integración social adolescente y evitar la reincidencia delictiva. Cfr. Berríos, Gonzalo: "La ley de responsabilidad penal del adolescente..." (nota 213), pp. 170-172.
} 
responsabilidad penal en los adolescentes, al mismo tiempo se reconoce que, por el evidente menor grado de desarrollo y madurez asociado al tramo etario al que pertenecen los mismos, su responsabilidad debe adoptar características y tener alcances diferentes de los que se aceptan respecto de personas adultas". ${ }^{215}$

Couso identifica las particularidades del menor, señalando que "[l]as sanciones para adolescentes deben ser menores que para los adultos, pues en general más condicionada está su conducta, tanto por la fase vital en que se encuentran (menor madurez, vinculada por ejemplo a menor posibilidad de comprender el valor social de ciertos bienes jurídicos, o de controlar sus impulsos), como por las menores competencias sociales con que cuentan (por ejemplo, para satisfacer sus necesidades por medios legítimos). Pero, además, dentro del grupo de los adolescentes, quienes cometen el delito bajo mayores condicionamientos sociales, familiares o individuales, menor culpabilidad tienen, y menor pena merecen: las desventajas y dificultades justifican una menor intervención penal ( $\mathrm{y}$ no una mayor, como ocurre bajo el pensamiento criminológico-correccionalista del sistema tutelar)" (las cursivas son nuestras). ${ }^{216}$

Los factores que muestran la menor culpabilidad o capacidad de culpabilidad del menor tienen que ver con su menor capacidad cognitivovalorativa y su menor capacidad de autodeterminación.

Esto se ve también reflejado en el régimen de penas. El artículo $8^{\circ}$ de la LRPA que establece la pena de amonestación señalando que está: "[...]dirigida a hacerle comprender la gravedad de los hechos cometidos y las consecuencias que los mismos han tenido o podrían haber tenido, tanto para la víctima como para el propio adolescente[...]" (las cursivas son nuestras). Tal regulación hace evidente un reconocimiento a la ausencia de imputabilidad más allá del énfasis en la rehabilitación que hace expreso el artículo 20 de la LRPA, y una tendencia hacia un régimen cercano a las medidas de seguridad. ${ }^{217}$

Igualmente, los artículos 53 a 55 de la Ley establecen la posibilidad de sustitución de la condena o su remisión condicional, luego de la condena e incluso una vez iniciado su cumplimiento, si es que sirve mejor para los objetivos de la condena (sustitución) o si dichos fines ya se encuentran cumplidos (remisión). ${ }^{218}$

\footnotetext{
${ }^{215}$ Hernández Basualto, Héctor: “El nuevo Derecho penal adolescente...” (nota 212), p. 197.

216 Couso Salas, Jaime: "La política criminal..." (nota 214), p. 219.

217 Cfr. Winter Etcheberry, Jaime: "La culpabilidad en la Ley de Responsabilidad Penal Adolescente", La Gaceta Jurídica 370, 2011, p. 276 y 277.

218 Artículo 53 LRPPA: Sustitución de condena. El tribunal encargado del control de la ejecución de las sanciones previstas en esta ley, de oficio o a petición del adolescente o su defensor, podrá sustituirla por una menos gravosa, en tanto ello parezca más favorable para la integración social del infractor y se hubiere iniciado su cumplimiento.

Para estos efectos, el juez, en presencia del condenado, su abogado, el Ministerio Público y un representante de la institución encargada de la ejecución de la sanción, examinará los antecedentes, oirá a los presentes y resolverá. A esta audiencia podrán asistir los padres del adolescente o las personas que legalmente hubieren ejercido la tuición antes de su privación de libertad y la víctima o
} 
Winter - Situaciones actuales en la frontera del principio de culpabilidad

Dichas constataciones no son meramente teóricas y debieran tener efectos prácticos concretos. Hernández ha puesto con claridad la atención en la revisión de la teoría del delito en el caso de los adolescentes. Además de una revisión del efecto de la edad en algunos tipos penales, ${ }^{219}$ las características de los menores pueden influir en algunos elementos del delito: su inmadurez y juventud pueden influir en errores de tipo y la determinación social puede influir en la adecuación social de la conducta, por citar algunos ejemplos. ${ }^{220}$ Particularmente interesante resulta su análisis en materia de culpabilidad, refiriéndose a, en primer lugar, la relevancia mayor que debe dárseles a las anomalías mentales, considerando "[...] la inmadurez y labilidad del sujeto, su relativa inestabilidad emocional $\mathrm{y}$, consecuentemente, la posibilidad de reacciones irracionales propias de una etapa de transición [...]",221 lo que debería poder llevar a una exclusión de responsabilidad en virtud del artículo $10 \mathrm{~N}^{\circ} 1$ del CP en casos que serían punibles en adultos. ${ }^{222}$ Similares efectos tendría en materia de exigibilidad penal, considerándose un estándar distinto para los menores, que serían más impresionables. ${ }^{223}$ Por último, en materia de error de prohibición, es evidente que el conocimiento del injusto será menos exigible tratándose de menores. ${ }^{224}$

Por otra parte, reconocer que se prescinde de la culpabilidad implica reconocer que estamos ante un sistema diferente, con un fundamento distinto,

su representante. La inasistencia de estos últimos no será nunca obstáculo para el desarrollo de la audiencia.

La resolución que se pronuncie sobre una solicitud de sustitución será apelable para ante la Corte de Apelaciones respectiva.

En caso alguno la internación en un régimen cerrado podrá sustituirse por una de las sanciones previstas en las letras e) o f) del artículo $6^{\circ}$.

Artículo 54 LRPA: Sustitución condicional de las medidas privativas de libertad. La sustitución de una sanción privativa de libertad podrá disponerse de manera condicionada. De esta forma, si se incumpliere la sanción sustitutiva, podrá revocarse su cumplimiento ordenándose la continuación de la sanción originalmente impuesta por el tiempo que faltare.

Artículo 55 LRPA: Remisión de condena. El tribunal podrá remitir el cumplimiento del saldo de condena cuando, en base a antecedentes calificados, considere que se ha dado cumplimiento a los objetivos pretendidos con su imposición. Para ello será aplicable lo dispuesto en los incisos segundo y tercero del artículo 53.

Para los efectos de resolver acerca de la remisión, el tribunal deberá contar con un informe favorable del Servicio Nacional de Menores.

Tratándose de una sanción privativa de libertad, la facultad de remisión sólo podrá ser ejercida si se ha cumplido más de la mitad del tiempo de duración de la sanción originalmente impuesta.

219 Hernández muestra que además de los efectos que expresamente tiene la LRPA en algunos delitos sexuales, en que se exige una diferencia de edad con la víctima, debe interpretarse una exigencia similar en otros delitos sexuales y otras conductas punibles como la sustracción de menores, donde la diferencia de edad parece un elemento relevante. Hernández Basualto, Héctor: "El nuevo Derecho penal adolescente..." (nota 212), pp. 202 a 205.

220 Ibid., pp. 205 a 208.

${ }^{221}$ Ibid., p. 208.

222 Ibid., p. 209.

${ }^{223}$ Ibid., p. 210-212.

${ }_{224}$ Ibid., p. 212-213. 
REJ - Revista de Estudios de la Justicia - No 17 - Año 2012

paralelo al de la responsabilidad general y no un mero subsistema que se diferencia sólo por elementos accidentales (como el régimen de penas). ${ }^{225}$ Esto tiene directa influencia en la aplicación de la agravante de reincidencia cuando el delito anterior hubiere sido cometido siendo menor. ${ }^{226}$ De considerarse como sistemas diferentes, no podría ser aplicada la agravante. Esto se ha argumentado, siendo en la práctica rechazado por los Tribunales. ${ }^{227}$

225 Winter Etcheberry, Jaime: "La culpabilidad...” (nota 217), p. 276 y 277.

226 Ibid.

${ }^{227}$ SCA de Concepción, 04.04.2011, Número de Ingreso 85-2011. 
Winter - Situaciones actuales en la frontera del principio de culpabilidad

\section{BIBLIOGRAFÍA}

* AMBOS, Kai: Der Allgemeine Teil des Völkerstrafrechts, Ed. Duncker \& Humbolt, Berlín, 2002.

"Superior Responsibility", en Cassese, Antonio, Gaeta, Paola y Jones, John R. W. D. (coords.), The Rome Statute of the International Criminal Court: A commentary, Oxford University Press, Oxford, 2002.

* BACIGALUPO, Enrique: Principios constitucionales del derecho penal, Ed. Hammurabi, Buenos Aires, 1999.

* BERRÍOS, Gonzalo: "La ley de responsabilidad penal del adolescente como sistema de justicia: análisis y propuestas", Política Criminal11, 2011, disponible en, http://www.politicacriminal.cl/Vol 06/n 11/Vol6N11A6.pdf (consultado el 12.10.2012).

* BOUVAIS, Pascal: "Countries with Criminal Liability, France", en Gobert, James y Pascal, Ana María, European Development in Corporate Criminal Liability, Ed. Routledge, Londres-Nueva York, 2011.

* BUStos ramírez, Juan y HORMAZÁBAL MALARÉE, Hernán, Lecciones de Derecho Penal, vol. I, Ed. Trotta, Madrid, 1997.

Lecciones de Derecho Penal, vol. II, Ed. Trotta, Madrid, 1999.

* COUSO SALAS, Jaime: "La política criminal para adolescentes y la Ley 20.084", Justicia y Derechos del Niño 11, 2009, disponible en, http://www.unicef.org/argentina/spanish/Justicia y Derechos 11 web.pdf (consultado el 12.10.2012).

* CREUS, Carlos: Derecho Penal, Parte especial, 6a ed., Ed. Astrea, Buenos Aires 1998.

* CURY, Enrique: Derecho Penal, Parte General, $7^{a}$ ed., Ediciones Universidad Católica de Chile, Santiago, 2005.

Personas jurídicas y derecho penal”, El Mercurio, 23.11.2009.

* DE DOELDER, Hans: "Criminal Liabilityof Corporations: A Dutch Update", en Sieber, Ulrich, Danneker, Gerhard, Kindhäuser, Urs, Vogel, Joachim y Walter, Tonio, Strafrecht und Wirtschaft Starfrecht: Festschrift für Klaus Tiedemann, Ed. Carl Heymanns, Münich, 2008.

* DE MAGLIE, Cristina: "Countries with criminal liability: Italy", en Gobert, James y Pascal, Ana María, European Development in Corporate Criminal Liability, Ed. Routledge, Londres-Nueva York, 2011.

* DÍEZ RIPOLLÉS, José Luis: "La responsabilidad penal de las personas jurídicas. Regulación española”, InDret1, 2012, disponible en http://www.indret.com/pdf/875.pdf (consultado el 12.10.2012).

* DILLON, Janis: "Countries with criminal liability. Country report: Slovenia", en Gobert, James y Pascal, Ana María, European Development in Corporate Criminal Liability, Ed. Routledge, Londres-Nueva York, 2011.

* EFE, "Sentencian a Anders Behring Breivik a 21 años de cárcel por atentados de Noruega", La Tercera, 24.08.2012, disponible en, http://www.latercera.com/noticia/mundo/2012/08/678-479743-9-sentencian-a-andersbehring-breivik-a-21-anos-de-carcel-por-atentados-de-noruega.shtml (consultado el 12.10.2012).

* ENGISCH, Karl: Die Lehre von der Willensfreiheit in der strafrechtsphilosophischen Doktrin der Gegenwart, Walter de Gruyter \& Co., Berlín, 1963.

* ETCheberry, Alfredo: Derecho Penal. Parte General, t. I, $3^{\text {a }}$ ed., Ed. Jurídica de Chile, Santiago, 1998.

"Reflexiones sobre Política Criminal. Intervención del Profesor Alfredo Etcheberry en la Ceremonia de su Investidura como Doctor Honoris Causa por la Universidad de Talca", Politica Criminal 7, 2009, disponible en,

http://www.politicacriminal.cl/Vol 04/n 07/Vol4N7D2.pdf (consultado el 12.10.2012). 
REJ - Revista de Estudios de la Justicia - No 17 - Año 2012

* FEIJOO SÁNCHEZ, Bernardo: “Autoría y participación en organizaciones empresariales complejas", en, del mismo, Cuestiones actuales de Derecho penal económico, Ed. B de F, Montevideo-Buenos Aires, 2009.

- FEUERBACH, Paul Johann Anselm: Lehrbuch des gemeinen in Deutschland gültigen peinlichen Rechts, 5a. ed., Ed. Georg Friederich Heyer, Gießen, 1812.

* Garrido MONTT, Mario: Derecho Penal, Parte General, t. I y II, Ed. Jurídica de Chile, Santiago, 2001.

* GOBERT, James: "Countries with criminal liability. Country Report: Finland". en Gobert, James y Pascal, Ana María, European Development in Corporate Criminal Liability, Ed. Routledge, Londres-Nueva York, 2011.

"Country Reports, Countries with Criminal Liability: UK". en Gobert, James y Pascal, Ana María, European Development in Corporate Criminal Liability, Ed. Routledge, Londres-Nueva York, 2011.

* GÓMEZ-JARA DÍEZ, Carlos: La Responsabilidad penal de las empresas en los EE.UU., Ed. Universitaria Ramón Areces, Madrid, 2006.

"Autoorganización empresarial y autorresponsabilidad empresarial: Hacia una verdadera responsabilidad penal de las personas jurídicas", Revista Electrónica de Ciencia Penal y Criminología 8, 2006, disponible en http://criminet.ugr.es/recpc/08/recpc08-05.pdf (consultado el 12.10.2012).

“¿Responsabilidad penal de todas las personas jurídicas?”, en Politica Criminal 10, 2010, disponible en http://www.politicacriminal.cl/Vol 05/n 10/Vol5N10D1.pdf (consultado el 12.10.2012).

* HAAS, Volker: "Kritik der Tatherrschaftlehre", ZStW 119, 2007.

* HEINE, Günther: Die strafrechtliche Verantwortlichkeit von Unternehmen, Ed. Nomos, BadenBaden, 1995.

* HeRnÁndez BASUALTO, Héctor: "El nuevo Derecho penal adolescente y la necesaria revisión de su "teoría del delito", Revista de Derecho 2, 2007, disponible en http://www.scielo.cl/pdf/revider/v20n2/art09.pdf (consultado el 12.10.2012).

"La introducción de la responsabilidad de las personas jurídicas en Chile", Política Criminal 9, 2010, disponible en, http://www.politicacriminal.cl/Vol 05/n 09/Vol5N9A5.pdf (consultado el 12.10.2012).

* HILL, Jennifer: "Corporate Criminal Liability in Australia: An Evolving Corporate Governance technique?", Journal of Business Law, (Working paper 03-10), 2003, disponible en http://papers.ssrn.com/sol3/papers.cfm?abstract $\mathrm{id}=429220$ (consultado el 12.10.2012).

* HOLMES, Oliver Wendell: The Common Law, Belknap Press of Harvard University Press (reimpresión), Cambridge, 2009.

* JAKOBS, Günther: Derecho Penal, Parte General, Cuello Contreras, Joaquín y Serrano González de Murillo, José Luis (trads.), Marcial Pons, Madrid, 1995.

"Strafbarkeit juristische Personen?", en Prittwitz, Cornelius; Baurmann, Michael; Günther, Klaus; Kuhlen, Lothar; Merkel, Reinhard; Nestler, Cornelius y Schulz, Lorenz (coords.), Festschrift für Klaus Lüderssen, Nomos, Baden-Baden, 2002.

* KAUFMANN, Arthur: Das Schuldprinæip, Carl Winter Universitätsverlag, Heidelberg, 1961.

* KAUfmann, Armin: La Dogmática de los Delitos de Omisión, Cuello Contreras, Joaquín y Serrano González de Murillo, José Luis (trads.), Marcial Pons, Madrid, 2006.

* KINDHÄUSER, Urs: Strafrecht. Allgemeiner Teil, 5a ed., Ed. Nomos, Baden-Baden, 2011.

* KUHLEN, Lothar: "Strafhaftung bei unterlassenem Rückruf gesundheitsgefährdender Produkte", NStZ12, 1990.

* KUnSEmÜller LOEBEnfELDER, Carlos: Culpabilidad y Pena, Ed. Jurídica de Chile, Santiago, 2001. 
Winter - Situaciones actuales en la frontera del principio de culpabilidad

* LAMPE, Ernst-Joachim: "Systemunrecht und Unrechtssystem", ZStW4, 1994.

* LAUfER, William S.: Corporate Bodies and Guilty Minds, The failure of Corporate Criminal Liability, The University Chicago Press, Chicago, 2006.

* MALDONADO FUENTES, Francisco: “¿Se puede justificar la aplicación copulativa de penas y medidas de seguridad? Estado actual de las posiciones doctrinales que buscan dicho objeto", Politica Criminal 12, 2011, disponible en, http://www.politicacriminal.cl/Vol 06/n 12/Vol6N12A5.pdf (consultado el 12.10.2012).

* MAÑALICH, Juan Pablo: "Organización Delictiva. Bases para su elaboración dogmática en el derecho penal chileno", Revista Chilena de Derecho 2, 2011, disponible en, http://www.scielo.cl/scielo.php?pid=S0718-34372011000200005\&script=sci arttext (consultado el 12.10.2012).

* MARTÍNEZ, Jenny S.: "Understanding Mens Rea in Command Responsibility, From Yamashita to Blaškić and Beyond", Oxford Journal of International Criminal Justice 3, 2007.

* MITGUTSCH, Ingrid: “Countries with criminal liability. Country report: Austria”, en Gobert, James y Pascal, Ana María, European Development in Corporate Criminal Liability, Ed. Routledge, Londres-Nueva York, 2011.

* NIETO MARTÍN, Adán: La responsabilidad penal de las personas jurídicas: un modelo legislativo, Ed. Iustel, Madrid, 2008.

* ORTIZ QUIROGA, Luis: "Responsabilidad de las personas jurídicas", El Mercurio, 15.12.2009.

* PASCAL, Ana María: “Countries with criminal liability. Country Report: Denmark", en Gobert, James y Pascal, Ana María, European Development in Corporate Criminal Liability, Ed. Routledge, Londres-Nueva York, 2011.

"Countries with criminal liability. Country report: Estonia", en Gobert, James y

Pascal, Ana María, European Development in Corporate Criminal Liability, Ed. Routledge, Londres-Nueva York, 2011.

"Countries with criminal liability. Country report: Romania", en Gobert, James y Pascal, Ana María, European Development in Corporate Criminal Liability, Ed. Routledge, Londres-Nueva York, 2011.

"Countries with criminal liability. Country Report: Poland", en Gobert, James y Pascal, Ana María, European Development in Corporate Criminal Liability, Ed. Routledge, Londres-Nueva York, 2011.

* PASCAL, Ana María y DILlON, Janis: "Countries with criminal Liability. Country report: Luxembourg”, en Gobert, James y Pascal, Ana María, European Development in Corporate Criminal Liability, Ed. Routledge, Londres-Nueva York, 2011.

* PASCAL, Ana María y RAMKISSOON, Melanie: "Countries with Criminal Liability. Country Report: Portugal”, en Gobert, James y Pascal, Ana María, European Development in Corporate Criminal Liability, Ed. Routledge, Londres-Nueva York, 2011.

* POLITOFF L., Sergio, MATUS A., Jean Pierre y RAMÍREZ G., María Cecilia: Lecciones de Derecho Penal, Parte General, 2a ed., Ed. Jurídica de Chile, Santiago, 2003.

* PUPPE, Ingeborg: "División del trabajo y de la responsabilidad en la actuación médica", InDret 4, 2006, disponible en http://www.indret.com/pdf/382 es.pdf (consultado el 05.12.2012).

* RAMKISSOON, Melanie: "Countries with criminal liability. Country Report. The Netherlands", en Gobert, James y Pascal, Ana María, European Development in Corporate Criminal Liability, Ed. Routledge, Londres-Nueva York, 2011.

"Countries with criminal Liability. Country Report: Belgium", en Gobert, James y Pascal, Ana María, European Development in Corporate Criminal Liability, Ed. Routledge, Londres-Nueva York, 2011.

* ROBINSON, Paul: "Mens Rea", en Dressler, Joshua, Encyclopaedia of crime\&justice, 2a ed., Ed. Macmillan Reference USA, Nueva York, 2002, disponible en, 
REJ - Revista de Estudios de la Justicia - No 17 - Año 2012

http://papers.ssrn.com/sol3/papers.cfm?abstract id=661161 (consultado con fecha 16.10.2012).

* ROTSCH, Thomas: "Die Rechtsfigur des Täters hinter dem Täter bei der Begehung von Straftaten im Rahmen organisatorischer Machtapparate und ihre Übertragbarkeit auf wirtschaftliche Organisationsstrukturen", NStZ10, 1998.

Individuelle Haftung in Großunternehmen, Ed. Nomos, Baden-Baden, 1998.

Einheitstäterschaft" statt Tatherrschaft, Ed. Mohr Siebeck, Tübingen, 2009.

"Criminal Compliance", InDret 1, 2012, disponible en http://www.indret.com/pdf/876a.pdf (consultado el 12.10.2012).

* ROXIN, Claus: Täterschaft und Tatherrschaft, 7a ed., Ed. Walter de Gruyter, Berlin-New York, 2000.

"El Dominio de Organización como forma independiente de Autoría Mediata", Revista de Estudios de la Justicia 7, 2006, disponible en, http://web.derecho.uchile.cl/cej/recej/RECEJ\%207/EL\%20DOMINIO\%20DE\%20L A $\% 20$ ORGANIZACION $\% 20$ COMO $\% 20$ FORMA $\% 20$ INDEPENDIENTE $\% 20$ DE $\% 2$ OAUTORIA\%20MEDIATA.pdf (consultado el 12.10.2012).

Strafrecht, Allgemeiner Teil, 4 ed., t.I, Ed. C.H. Beck, München, 2006.

* SCHÜNEMANN, Bernd: Unternehmenskriminalität und Strafrecht, Ed. Carl Heymanns, Colonia, 1979.

"Responsabilidad penal en el marco de la empresa. Dificultades relativas a la individualización de la imputación”, ADPCP LV, 2002.

* SILVA SÁNCHEZ, Jesús María, "La Responsabilidad jurídica de las personas jurídicas y las consecuencias accesorias del art. 129 del Código Penal", en Manuales de formación continuada, Consejo General del Poder Judicial, 2001.

* SOlOVEICIKAS, Deividas: "Countries with criminal liability. Country report: Lithuania”, en Gobert, James y Pascal, Ana María, European Development in Corporate Criminal Liability, Ed. Routledge, Londres-Nueva York, 2011.

* STRATENWERTH, Gunther y KUHLEN, Lothar: Strafrecht Allgemeiner Teil. Die Straftat, 6a ed., Ed. Franz Vahlen, München, 2011.

* TIEDEMANN, Klaus: Wirstschaftsstrafrecht, 2a ed, Ed. Carl Heymanns, Berlin, 2007.

* TOMBS, Steve: "Corporations and Health and Safety", en Minkes, John y Minkes, Leonard (eds.), Corporate and White-Collar Crime, Ed. Sage, Los Angeles-Londres-Nueva Delhi-Singapur, 2008.

* VAN WEEZEL, Alex: "Contra la responsabilidad penal de las personas jurídicas”, Política Criminal 9, 2010, disponible en, http://www.politicacriminal.cl/Vol 05/n 09/Vol5N9A3.pdf (consultado el 12.10.2012).

* VELOZO, Francisco: "Un retroceso de siglos", Estrategia, 4.12.2009, disponible en, http://www.estrategia.cl/detalle columnista.php?cod=2908 (consultado el 16.10.2012).

* WESSELS, Johannes y BEULKE, Werner: Strafrecht, Allgemeiner Teil, 41a ed., Ed. C. F. Müller, Heidelberg-München-Landsberg-Frechen-Hamburg, 2011.

* Winter ETCHEBERRY, Jaime: La responsabilidad de los superiores en el Derecho penal internacional (tesis de grado sin publicar), Facultad de Derecho, Universidad de Chile, Santiago, 2009.

"La culpabilidad en la Ley de Responsabilidad Penal Adolescente", La Gaceta Jurídica 369, 2011. 